\title{
Expanding standards in viromics: in silico evaluation of dsDNA viral genome identification, classification, and auxiliary metabolic gene curation
}

\author{
Akbar Adjie Pratama ${ }^{1,2}$, Ben Bolduc ${ }^{1,2}$, Ahmed A. Zayed ${ }^{1,2}$, Zhi-Ping Zhong ${ }^{1,2}$, Jiarong Guo ${ }^{1,2}$, Dean Vik ${ }^{1,2}$, Maria

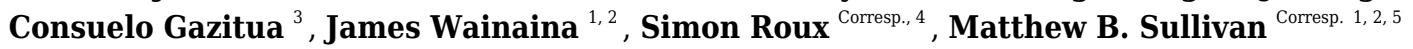 \\ ${ }^{1}$ Department of Microbiology, Ohio State University, Columbus, $\mathrm{OH}$, United States \\ 2 Center of Microbiome Science, Ohio State University, Columbus, $\mathrm{OH}$, United States \\ 3 Viromica Consulting, Santiago, Chile \\ 4 Lawrence Berkeley National Lab, Berkeley, CA, United States \\ 5 Department of Civil, Environmental and Geodetic Engineering, Ohio State University, Columbus, Ohio, United States \\ Corresponding Authors: Simon Roux, Matthew B. Sullivan \\ Email address: sroux@lbl.gov, sullivan.948@osu.edu
}

Background:Viruses influence global patterns of microbial diversity and nutrient cycles. Though viral metagenomics (viromics), specifically targeting dsDNA viruses, has been critical for revealing viral roles across diverse ecosystems, its analyses differ in many ways from those used for microbes. To date, viromics benchmarking has covered read pre-processing, assembly, relative abundance, read mapping thresholds and diversity estimation, but other steps would benefit from benchmarking and standardization. Here we use in silico-generated datasets and an extensive literature survey to evaluate and highlight how dataset composition (i.e. viromes vs bulk metagenomes) and assembly fragmentation impact (i) viral contig identification tool, (ii) virus taxonomic classification, and (iii) identification and curation of auxiliary metabolic genes (AMGs).

Results:The in silico benchmarking of five commonly used virus identification tools show that genecontent-based tools consistently performed well for long ( $\geq 3 \mathrm{kbp}$ ) contigs, while $k$-mer- and blast-based tools were uniquely able to detect viruses from short ( $<3 \mathrm{kbp}$ ) contigs. Notably, however, the performance increase of $k$-mer- and blast-based tools for short contigs was obtained at the cost of increased false positives (sometimes up to $\sim 5 \%$ for virome and $\sim 75 \%$ bulk samples), particularly when eukaryotic or mobile genetic element sequences were included in the test datasets. For viral classification, variously sized genome fragments were assessed using gene-sharing network analytics to quantify drop-offs in taxonomic assignments, which revealed correct assignations ranging from $\sim 95 \%$ (whole genomes) down to $\sim 80 \%$ (3 kbp sized genome fragments). A similar trend was also observed for other viral classification tools such as VPF-class, ViPTree and VIRIDIC, suggesting that caution is warranted when classifying short genome fragments and not full genomes. Finally, we highlight how fragmented assemblies can lead to erroneous identification of AMGs and outline a best-practices workflow to curate candidate AMGs in viral genomes assembled from metagenomes.

Conclusion:Together, these benchmarking experiments and annotation guidelines should aid researchers seeking to best detect, classify, and characterize the myriad viruses 'hidden' in diverse sequence datasets.

Keywords: Benchmarks, standard operating procedure, viruses, viromics, ecology 


\section{Expanding standards in viromics: in silico evaluation of dsDNA viral genome}

2 identification, classification, and auxiliary metabolic gene curation

3

4 Akbar Adjie Pratama ${ }^{1,2}$, Ben Bolduc ${ }^{1,2}$, Ahmed A. Zayed ${ }^{1,2}$, Zhi-Ping Zhong ${ }^{1,2}$, Jiarong Guo ${ }^{1,2}$,

5 Dean Vik ${ }^{1,2}$, M. Consuelo Gazitúa ${ }^{3}$, James Wainaina ${ }^{1,2}$, Simon Roux $^{4 *} \&$ Matthew B.

6 Sullivan ${ }^{1,2,5^{*}}$

7

$8{ }^{1}$ Department of Microbiology, Ohio State University, Columbus, OH, United States of America.

$9{ }^{2}$ Center of Microbiome Science, Ohio State University, Columbus, OH, United States of

10 America.

$11{ }^{3}$ Viromica Consulting, Santiago, Chile.

$12{ }^{4}$ Lawrence Berkeley National Laboratory, Berkeley, CA, United States of America.

$13{ }^{5}$ Department of Civil, Environmental and Geodetic Engineering, Ohio State University, 14 Columbus, $\mathrm{OH}$, United States.

$16 *$ Correspondence:

17 Simon Roux,

18 JGI - Joint genome institute, Lawrence Berkeley National Laboratory

19 sroux@lbl.gov.

21 Matthew B. Sullivan,

22496 W 12th Ave, Riffe Building 947, Columbus, OH 43210

23 sullivan.948@osu.edu. 


\section{Abstract}

\section{Background:}

Viruses influence global patterns of microbial diversity and nutrient cycles. Though viral metagenomics (viromics), specifically targeting dsDNA viruses, has been critical for revealing viral roles across diverse ecosystems, its analyses differ in many ways from those used for microbes. To date, viromics benchmarking has covered read pre-processing, assembly, relative abundance, read mapping thresholds and diversity estimation, but other steps would benefit from benchmarking and standardization. Here we use in silico-generated datasets and an extensive literature survey to evaluate and highlight how dataset composition (i.e. viromes vs bulk metagenomes) and assembly fragmentation impact ( $i$ ) viral contig identification tool, (ii) virus taxonomic classification, and (iii) identification and curation of auxiliary metabolic genes 38 (AMGs).

\section{Results:}

The in silico benchmarking of five commonly used virus identification tools show that genecontent-based tools consistently performed well for long ( $\geq 3 \mathrm{kbp}$ ) contigs, while $k$-mer- and blast-based tools were uniquely able to detect viruses from short $(<3 \mathrm{kbp})$ contigs. Notably, however, the performance increase of $k$-mer- and blast-based tools for short contigs was obtained at the cost of increased false positives (sometimes up to $\sim 5 \%$ for virome and $\sim 75 \%$ bulk samples), particularly when eukaryotic or mobile genetic element sequences were included in the test datasets. For viral classification, variously sized genome fragments were assessed using gene-sharing network analytics to quantify drop-offs in taxonomic assignments, which revealed correct assignations ranging from $\sim 95 \%$ (whole genomes) down to $\sim 80 \%$ (3 kbp sized genome fragments). A similar trend was also observed for other viral classification tools such as VPFclass, ViPTree and VIRIDIC, suggesting that caution is warranted when classifying short genome fragments and not full genomes. Finally, we highlight how fragmented assemblies can candidate AMGs in viral genomes assembled from metagenomes.

\section{Conclusion:}


57

58

59

60

61

62

63

64

65

66

67

68

69

70

71

72 73

Together, these benchmarking experiments and annotation guidelines should aid researchers seeking to best detect, classify, and characterize the myriad viruses 'hidden' in diverse sequence datasets.

Keywords: Benchmarks, standard operating procedure, viruses, viromics, ecology

\section{Introduction}

Viruses that infect microbes play significant roles across diverse ecosystems. For example, in marine systems, viruses are now broadly recognized to modulate biogeochemical cycles via lysis (e.g. heterotrophic prokaryotes lysis) (Fuhrman, 1999; Wilhelm \& Suttle, 1999), alter evolutionary trajectory of core metabolisms via horizontal gene transfer (e.g. Sullivan et al., (2006)), and impact the downward flux of carbon that helps the oceans buffer us (humans) against climate change (Guidi et al., 2016; Lara et al., 2017; Laber et al., 2018; Blanc-Mathieu et al., 2019).

Viromics (viral metagenomics) has helped further our understanding of marine viral genomic diversity, and ecosystem roles (Mizuno et al., 2013; Anantharaman et al., 2014; Coutinho et al., 2017; Nishimura et al., 2017a; Ahlgren et al., 2019; Haro-Moreno, Rodriguez-Valera \& LópezPérez, 2019; Ignacio-espinoza, Ahlgren \& Fuhrman, 2019; Luo et al., 2020). Ecologically, we now have global ocean catalogs approaching $200 \mathrm{~K}$ dsDNA viruses that have been used to provide ecological maps of community structure and drivers (Mizuno et al., 2013; Brum et al., 2015; Roux et al., 2016; Coutinho et al., 2017; Gregory et al., 2019), and to formally (Gregory et al., 2019) and empirically (Gregory et al., 2019; Haro-Moreno, Rodriguez-Valera \& LópezPérez, 2019) demonstrate that these viral populations represent species. Biogeochemically, viral roles in biogeochemistry now appear more nuanced as viruses impact biogeochemical cycling not only by lysing their microbial hosts as has been studied for decades (Fuhrman, 1999; Wilhelm \& Suttle, 1999), but also by reprogramming cellular biogeochemical outputs either broadly through viral take-over and infection (the 'virocell') or more pointedly by expressing 'auxiliary metabolic genes' (AMGs) during infection that alter specific metabolisms of the cell (Breitbart et al., 2007; Lindell et al., 2007; Rosenwasser et al., 2016; Howard-Varona et al., 2020). While AMGs were initially discovered in cultures [e.g. photosynthesis genes (Mann et al., 2003)], viromics has drastically expanded upon these to now also include dozens of AMGs for 
88 functions across central carbon metabolism, sugar metabolism, lipid-fatty acid metabolism,

89 signaling, motility, anti-oxidation, photosystem I, energy metabolism, iron-sulfur, sulfur, DNA

90 replication initiation, DNA repair, and nitrogen cycling (Clokie et al., 2006; Sharon et al., 2007;

91 Dinsdale et al., 2008; Millard et al., 2009; Wommack et al., 2015; Hurwitz, Brum \& Sullivan,

92 2015; Roux et al., 2016; Breitbart et al., 2018; Roitman et al., 2018; Ahlgren et al., 2019; Gazitúa

93 et al., 2020; Kieft et al., 2020; Mara et al., 2020).

94 Beyond the oceans, viromics is also providing novel biological insights in e.g. humans (Lim

95 et al., 2015; Norman et al., 2015; Reyes et al., 2015; Aiemjoy et al., 2019; Clooney et al., 2019;

96 Fernandes et al., 2019; Gregory et al., 2020b), soils (Zablocki, Adriaenssens \& Cowan, 2015;

97 Trubl et al., 2018; Jin et al., 2019; Li et al., 2019; Santos-Medellin et al., 2020), and extreme

98 environments (Adriaenssens et al., 2015; Scola et al., 2017; Bäckström et al., 2019; Zhong et al.,

99 2020). Together these studies provide baseline ecological understanding of viral diversity and

100 functions across diverse ecosystems.

101 Critically, however, viromics remains an emerging science frontier with methods and

102 standards very much in flux. To date, standardization efforts have included ( $i$ ) establishing

103 quantitative data generation methods (Yilmaz, Allgaier \& Hugenholtz, 2010; Duhaime et al.,

104 2012; Hurwitz et al., 2013; Solonenko \& Sullivan, 2013; Conceição-Neto et al., 2015; Roux et

105 al., 2017), and (ii) analytical benchmarks for read pre-processing, metagenomics assembly, and

106 thresholds for relative abundance, read mapping and diversity estimation (Brum et al., 2015;

107 Gregory et al., 2016; Roux et al., 2017). Further, though not from viral particle derived

108 metagenomes (viromes), related efforts have also been made to provide recommendations for

109 how best to analyze viruses in bulk metagenomic samples (Paez-Espino et al., 2016, 2017;

110 Dutilh et al., 2017; Emerson et al., 2018).

111 Here we contribute to this growing set of community-driven benchmarks and guidelines.

112 Specifically, we use in silico datasets that mimic viromes (specifically of dsDNA viruses) and

113 bulk metagenomes with varied inference from non-virus 'distractor' sequences to evaluate $(i)$

114 options for viral identification, (ii) genomic fragment sizes for viral classification via gene-

115 sharing networks, as well as (iii) provide guidelines for best practices for the evaluation of

116 candidate AMGs.

117

118 Materials and Methods

PeerJ reviewing PDF | (2020:11:55638:2:0:NEW 20 Apr 2021) 


\section{Dataset}

121 Datasets used in this study included genomes from: $(i)$ NCBI virus RefSeq v.203 (released 122 December 2020); to avoid including the same genomes used in any of the viral identification 123 tools and vConTACT v2, we chose only complete genomes released after May 2020 (1,213

124 genomes, see Table S1), (ii) Bacteria RefSeq v.203 (174,973,817 genomic scaffolds), (iii) 125 archaea RefSeq v.203 (2,116,989 genomic scaffolds), (iv) NCBI plasmids v.203 (1,339,171 126 genomes), and (iv) Human GRCh38 as the eukaryotic dataset. All datasets were downloaded 127 from NCBI RefSeq, last accessed in December 2020 (the links are listed in the "availability of 128 data and materials" section below). In addition, we also added $\sim 142$ dsDNA cyanophage 129 genomes to include a set of closely related genomes, as can sometimes be obtained from 130 viromics experiments (Table S1) (Gregory et al., 2016).

\section{Dataset simulation}

133 In silico simulations were adapted to benchmark the viromics pipelines for $(i)$ virus

134 identification and ( $\mathrm{ii}$ ) virus classification. The overall framework of dataset simulation strategies

135 is shown in Figure 1. The simulation created four randomized subsampled datasets that were

136 further fragmented to mimic fragmented assemblies of viromes and bulk metagenomes for viral

137 contig identification and classification. An in-house script was used to (non-overlapping)

138 fragment viral, eukaryotic, prokaryotic, and plasmid sequences into non-overlapping fragments

139 of different lengths, i.e. $L=500 \mathrm{bp}, 1 \mathrm{kbp}, 3 \mathrm{kbp}, 5 \mathrm{~kb}, 10 \mathrm{kbp}$, and $20 \mathrm{kbp}$. Non-overlapping

140 fragments from each sequence category (viral, prokaryotic, eukaryotic, plasmid) were then 141 combined to reflect mock communities' composition (see below). These mixed datasets were

142 used to benchmark viral contigs identification tools (Figure 1), while benchmarking of virus 143 classification was performed only on fragmented sequences from viral RefSeq (Figure 1).

Mock communities

146 The four mock communities (with four replicates for each dataset) were randomly 147 constructed to include different virus, prokaryotic, eukaryotic and plasmid sequences in ratios 148 (Figure 1) that varied to represent communities enriched in viral genomes (Roux et al., 2015), i.e. 
149 "virome_1 (up to 20,021 sequences; ratio, 10:1:1:0.01)" and "virome_2 (up to 20,021 sequences;

150 ratio, 10:1:0.01:1)" or cellular genomes, i.e. "bulk_1 (up to 270,271 sequences; ratio,

151 1:10:0.01:10)" and "bulk_2 (up to 22,035 sequences; ratio, 1:10:1:1)" (Figure 1). To further

152 investigate the potential source of errors in viral contigs identification, we also fragmented

153 datasets consisting only of archaea, plasmid and eukaryotes (human; Figure 1).

154

\section{Viral contig identification}

156 The tools used for viral identification included VirSorter (Roux et al., 2015), MetaPhinder

157 (Jurtz et al., 2016), MARVEL (Amgarten et al., 2018), DeepVirFinder (Ren et al., 2019), and

158 VIBRANT (Kieft, Zhou \& Anantharaman, 2020). Different cutoffs were applied for each of the

159 tools, as follows, $(i)$ we used two different versions of VirSorter, v1.0.5 and v1.10. VirSorter

160 v1.05 used the viromedb database, while VirSorter v1.10 included the same viromedb database,

161 as well as the Xfam database (Emerson et al., 2018; Gregory et al., 2019). For VirSorter (version

162 1.0.5 and 1.1.0; with "--db 2 --virome --diamond"), different cutoffs were used and compared:

163 either all VirSorter predictions were considered as viruses (categories 1-6), or, only predictions

164 of categories 1, 2, 4, and 5 was considered as viruses. For DeepVirFinder (version 1.0), we used

165 three score cutoffs: $\geq 0.7, \geq 0.9$ and $\geq 0.95$ and $p$-values $\leq 0.05$. For MARVEL (version 0.2 ), two

166 score cutoffs were used: $\geq 70 \%$ and $\geq 90 \%$. Finally, for VIBRANT we used two different

167 versions, i.e. version 1.1.0 and version 1.2.0; with "-virome" and no "-virome" setting), and

168 MetaPhinder, default settings were used. The performance metrics to evaluate the efficiency of

169 each tool were:

170

$$
M C C=\frac{(T P \times T N)-(F P \times F N)}{\sqrt{(T P+F P)(T P+F N) \times(T N+F P)(T N+F N)}}
$$

171

172

Where MMC is Matthews's correlation coefficient, TP is true positive, TN is true negative,

$173 \mathrm{FP}$ is false positive, and FN is false negative. MCC values range between -1 to 1 , with 1

174 indicating perfect efficiency (Chicco \& Jurman, 2020).

175

$$
\text { Recall }=\frac{T P}{T P+F P}
$$

176

177

178

Where TP is true positive, and FP is false positive.

$$
\text { False-discovery rate }=\frac{F P}{F P+T N}
$$


179

180

181

182

183

184

185

186

187

188

189

190

191

192

193

194

195

196

197

198

199

200

201

202

203

204

205

206

207

208

209

Where FP is false positive, and TN is true negative.

$$
\text { Accuracy }=\frac{T P+T N}{T P+T N+F P+F N}
$$

Where TP is true positive, $\mathrm{TN}$ is true negative, $\mathrm{FP}$ is false positive, and $\mathrm{FN}$ is false negative.

$$
F 1=\frac{2 T P}{2 T P+F P+F N}
$$

Where $\mathrm{TP}$ is true positive, $\mathrm{TN}$ is true negative, $\mathrm{FP}$ is false positive, and $\mathrm{FN}$ is false negative.

$$
P V V=\frac{T P}{T P+F P}
$$

Where PVV is positive predictive value, TP is true positive, TN is true negative, FP is false positive, and $\mathrm{FN}$ is false negative.

$$
\text { Specificity }=\frac{T N}{T N+F P}
$$

Where TN is true negative, and FP is false positive.

\section{Statistical analysis}

A Wilcoxon test was used to compare the overall performance of viral identification, on the basis of fragment length (with $20 \mathrm{kbp}$ as a reference group), including MCC, recall, false discovery, accuracy, F1, PVV, and specificity. The analysis was done using the R program (https://www.r-project.org/).

\section{Viral classification}

To evaluate the impact of fragmented assembly on a gene-sharing network-based viral classification, we leveraged vConTACT v2 (Jang et al., 2019) and used fragmented viral RefSeq genomes of different lengths (i.e. $500 \mathrm{bp}, 1 \mathrm{kbp}, 3 \mathrm{kbp}, 5 \mathrm{kbp}, 10 \mathrm{kbp}$, and $20 \mathrm{kbp}$ ) with default parameters. Furthermore, we also applied vConTACT v2 to complete genomes as a control dataset. It is worth noting that vConTACT v2 (originally) uses RefSeq v.85 (now has been updated to RefSeq v.99) as a reference database and manually validated ICTV taxonomies (ICTV Master Species List v1.3- February 2018) (Jang et al., 2019). The metrics used were those of Jang et al., (2019) including: (i) accuracy (Acc), (ii) clustering-wise separation (Sep), (iii) the 
210 positive predictive value (PPV), (iv) clustering-wise sensitivity (Sn), (v) cluster-wise separation

$211\left(\operatorname{Sep}_{c l}\right)$, and (vi) complex (ICTV taxonomy)-wise separation ( $\left.\operatorname{Sep}_{c o}\right)$. The formulas are available

212 in Jang et al., (2019).

213 In addition to vConTACT v2, we also evaluated the impact of fragmented assembly on viral

214 classification using VPF-class (protein family based) (Pons et al., 2021), VipTree (genome-wide

215 similarities-based) (Nishimura et al., 2017b), and VIRIDIC (BLASTN-based) (Moraru, Varsani

216 \& Kropinski, 2020). To evaluate the result, for VPF-class, we used taxonomic assignation of

217 fragments with confidence score (CS) of $\geq 0.2$ and membership ratio (MR) of $\geq 0.2$, that have

218 been reported to result in 100\% of accuracy (Pons et al., 2021). For VIRIDIC and ViPTree, since

219 no taxonomic assignation is automatically generated, we used the similarity and distance

220 matrices provided by these tools to evaluate their performance on fragmented genomes, by

221 comparing the similarity/distances obtained from genome fragments to the ones obtained from

222 complete genomes (Nishimura et al., 2017b; Moraru, Varsani \& Kropinski, 2020).

223

224 AMG curation analysis

225 Recommendations and best practices for AMG curation were based on a survey of the recent 226 AMG literature, including especially Roux et al., (2016), Enault et al., (2017), Breitbart et al.,

227 (2018), Kieft et al., (2020). To illustrate the major challenges in the AMG identification process, 228 we used DRAMv (Shaffer et al., 2020) to identify candidate AMGs in virus genomes from 229 (Emerson et al., 2018; Mara et al., 2020). The following parameters were used: AMGs score of

230 1-3 and AMG flag of -M and -F. To verify the functional annotation of the candidate AMGs, we 231 manually checked the genomic context of the viral contigs, i.e. the annotation of the neighboring 232 genes (especially the presence of viral hallmark and viral-like genes), and the position of AMG

233 with respect to the contig's edge. Next, we then manually looked for the presence of

234 promoter/terminator regions using BPROM (Linear discriminant function (LDF) $>2.75$;

235 (Richardson \& Watson, 2013)), and ARNold (default setting; (Macke et al., 2001)). Conserved

236 regions and active sites in the protein sequences were analyzed using PROSITE (Sigrist et al.,

237 2013) and HHPred (Zimmermann et al., 2018) using the PROSITE collection of motifs

238 (ftp://ftp.expasy.org/databases/prosite/prosite.dat), and PDB_mmCIF70_14_Oct (default)

239 databases, respectively. For protein structural similarity, we used Phyre $^{2}$ (confidence $>90 \%$ and

$24070 \%$ coverage; (Kelly et al., 2015)), and predicted quaternary structures using SWISS-MODEL 
241 with a Global Model Quality Estimation (GMQE) score above 0.5 (Waterhouse et al., 2018).

242 Eventually, we selected one representative example for different typical cases of either genuine

243 AMGs or false-positive detections, which are visualized using genome maps drawn with EasyFig

244 (Sullivan, Petty \& Beatson, 2011).

\section{Results and Discussion}

247

248 Establishment of mock communities for in silico testing

249 We first benchmarked and compared strategies for identification of viruses across different

250 types of metagenomes. Researchers have identified viruses from virus-enriched metagenomes

251 (viromes), as well as bulk and/or cellular metagenomes that are typically dominated by

252 prokaryotic or eukaryotic sequences, all with variable representation of other mobile elements

253 (e.g. plasmids and transposons). We thus established mock community datasets that included

254 viral, prokaryotic, eukaryotic and plasmid sequences in varied ratios to represent a diversity of

255 datasets likely to be encountered in environmental samples (Figure 1).

256 Briefly, two mock communities represented viromes and two represented bulk metagenomes, 257 with ratios of virus: prokaryote: eukaryote: plasmid sequences as follows: "virome_1" ratio = 10:1:1:0.01, "virome_2" ratio $=10: 1: 0.01: 1$, "bulk_1" ratio $=1: 10: 0.01: 10$ and "bulk_2" ratio $=$ 1:10:1:1 (see Methods and Materials for details, Figure 1). Clearly benchmarking are needed for other viral types since our focus here was dsDNA viruses. It is also worth noting that to better mimic viral populations in natural system, we complemented RefSeq genomes by specifically adding closely related genomes to the datasets from the only such deeply sequenced 'reference' dataset available (cyanophages (Gregory et al., 2016), see Materials and Methods). To reflect the

264 fragmented assembly typically obtained from short-read metagenomes, we extracted random subsets of varying length $(500 \mathrm{bp}-20 \mathrm{kbp})$ from these genomes, which were then combined at different ratios. Importantly, for viral RefSeq dataset, we only consider those newly submitted viral genome beyond May 2020, this to avoid including genomes that were used in training of any of the tools benchmarked here. 
270 Comparison of viral identification tools

271 Several bioinformatic analysis tools have been developed to identify viruses from

272 metagenomes (Table 1), using three major approaches: $(i)$ similarity to known viruses, (ii) gene

273 content/features, and (iii) $k$-mer frequency (i.e. nucleotide composition). Here, we first compared

274 the performance of the most commonly used viral identification tools: VirSorter (Roux et al.,

275 2015), MetaPhinder (Jurtz et al., 2016), MARVEL (Amgarten et al., 2018), DeepVirFinder (Ren

276 et al., 2019), and VIBRANT (Kieft, Zhou \& Anantharaman, 2020) against our suite of mock

277 communities. We attempted to include two additional tools PHASTER (Arndt et al., 2017), and

278 VirMiner (Zheng et al., 2019) -- but these did not scale and were eventually not included in the

279 test results presented here. A range of parameters and cutoffs (see Methods and Materials for

280 details) were used to assess the performance of each tool across different fragment sizes (ranging

$281500 \mathrm{bp}-20 \mathrm{kbp})$. Tool performance was evaluated using the following metrics: $(i)$ "efficiency",

282 assessed using Matthews correlation coefficient, an overall statistic for assessing the recall and

283 false-discovery, which this measure (MCC) offers a more informative and truthful evaluation

284 than accuracy and F1 score (Chicco \& Jurman, 2020), (ii) recall, (iii) false-discovery rate, (iv)

285 accuracy, (v) F1, (vi) PVV, and (vi) specificity (see the formulas in Materials and Methods).

286 Overall, we found that viral contigs were better identified (increased efficiency, MCC) as

287 fragment sizes increased, and this was true for all tools evaluated (Figure 2 and Figure S1-4,

288 Wilcoxon test, $p$-value $\leq 0.0001)$. However, tools based on gene content, i.e. VIBRANT,

289 MARVEL, and VirSorter (v1.05 and v1.10) decreased sharply in efficiency (MCC) with input

290 sequences $\leq 3 \mathrm{kbp}$ and particularly $\leq 1 \mathrm{kbp}$ (Fig. 2A-C), whereas this decrease was less

291 pronounced for DeepVirFinder ( $k$-mer based) and MetaPhinder (BLASTN based) at these

292 smaller size ranges (MCC values $\sim 0.20-0.625$; Figure 2A). Notably, the trade-off of this

293 efficiency was a higher false-discovery that reached as much as $\sim 5 \%$ for virome and $\sim 80 \%$ for

294 bulk samples in our mock communities as compared to $<1 \%$ when longer fragments were used

295 (Figure 2C).

296 We next explored how permissive versus conservative parameter cutoffs impacted viral

297 identification based on permissive and conservative cutoffs recommended for each tool (Roux et

298 al., 2015; Jurtz et al., 2016; Amgarten et al., 2018; Ren et al., 2019; Kieft, Zhou \& 
299 Anantharaman, 2020) (see Materials and Methods, and Figure 2). As expected, 'conservative'

300 thresholds led to lower recall and lower false-discovery than 'permissive' for all tools (Figure 2).

301 This illustrates the trade-off that researchers are faced with maximizing viral identification

302 (especially for fragment sizes $\leq 3 \mathrm{kbp}$ ) using 'permissive' cutoffs and/or tools not based on gene

303 content will almost always be associated with a higher rate of false-discovery. Ultimately, the

304 initial research question of the study has to be considered to make the decision of which type of

305 cutoffs to use.

306 Finally, we evaluated whether false-positive detections were associated with specific types of 307 non-viral sequences, including other mobile genetic elements and "novel" microbial genomes.

308 To this end, we generated datasets composed only of archaea, plasmid, or eukaryotic sequences,

309 and measured false-discovery rates across the viral identification tools (Figure S3). It is

310 important to note however that, to our knowledge, there is currently no "clean" plasmid database

311 that is not also containing phages/viruses' genome. Therefore, our benchmark is based on a

312 cleaning based on "complete" plasmid/phages, and primarily looking at how genome

313 fragmentation impacts the delineation of plasmid vs phage. Most tools showed an especially high

314 false-discovery rate for plasmid and/or eukaryotic sequences, including VIBRANT v.1.2.0 when

315 using the virome flag (highest in eukaryote up to $>90 \%$ false-discovery, while other version of

316 VIBRANT is less affected), MetaPhinder (highest in plasmid up to $>40 \%$ false-discovery),

317 MARVEL (up to $20 \%$ false discovery for plasmid dataset), and VirSorter when using the

318 virome flag (up to $24 \%$ false-discovery in eukaryote datasets) (Figure S3). This suggests the

319 data used to train these tools may have under-represented eukaryotic and/or plasmid sequence

320 and highlights the importance of including diverse non-viral sequences in a balanced training set

321 when establishing machine-learning based viral contig detection tools, as previously highlighted

322 (Ponsero \& Hurwitz, 2019; Kieft, Zhou \& Anantharaman, 2020). Overall, two tools stand out in

323 terms of maintaining the lowest false-discovery across the datasets: gene-content based VirSorter

324 (conservative cutoff) and MARVEL (score $\geq 90 \%$ ).

325 Together these comparisons suggest that viral identification efficiency increases with

326 fragment length, and almost all tools are able to identify true viral contigs of $10 \mathrm{kbp}$ or longer. At

327 length $>3 \mathrm{kbp}$, "gene-content based tools" are able to maximize viral recall and minimize false

328 discovery at either permissive or conservative cutoffs, with VirSorter and MARVEL performing

329 best under conditions where "distractor genomes" (e.g. eukaryote, DPANN-archaea or plasmids) 
330 are expected to be prevalent. For researchers specifically aiming to identify short ( $<3 \mathrm{kbp})$ viral

331 genome fragments, $k$-mer based tools (DeepVirFinder) and BLAST-based tool (MetaPhinder)

332 would be the preferred choices, although while being aware of the potential high rate of false-

333 positive detections, especially in samples where distractor genomes are expected to be prevalent.

335 Virus classification using fragmented data in gene-sharing networks

336 Once contigs from metagenomic assemblies are identified as viral, the next challenge a

337 researcher faces is to determine what kind of virus they represent. Gene-sharing network

338 analytics have emerged as a means to semi-automate such classification, and taxonomic

339 assignations for whole genomes are robust even when the network includes varying amounts of

340 fragmented genomes (Jang et al., 2019), but no studies have evaluated the taxonomic

341 assignations of fragmented genomes themselves. Because viral genomes assembled from

342 metagenomes are often partial, we sought to better understand how gene-sharing network

343 approaches would perform for metagenome-derived viral sequences at various fragment lengths.

344 To answer this question, we first established a dataset of known genomes and then

345 fragmented it to five fragment sizes that are commonly obtained from virome assemblies (Roux

346 et al., 2017). Next, we evaluated the accuracy of taxonomic assignments for the variously sized

347 genome fragments against those from complete genomes. Our results showed the percentage of

348 sequences accurately assignable to specific viral taxa increased with fragment length.

349 Specifically, the percentage of sequences clustered in a vConTACT v2 gene-sharing network

350 increased from $61 \%$ to $>80 \%$ from $3 \mathrm{~kb}$ to fragment to complete genomes (Figure $3 \mathrm{~A}$ ). This

351 difficulty in robustly integrating short genome or genome fragments in a gene-sharing network is

352 further illustrated by the network topology itself, which shows a much higher fragmentation of

353 the network for $3 \mathrm{~kb}$ fragment compared to complete genomes, accompanied by an inflated

354 number of "new VCs" and a higher number of unclustered sequence (whether outlier,

355 overlapping, or singleton, Figure S5). In addition to this lower rate of clustered sequences, short

356 fragments also displayed a reduced percentage of sequences assigned to the correct genus

357 (Figure S6) and overall lower performance across all vConTACT v2 metrics tested (Figure S7).

358 This is consistent with the original vConTACT v2 benchmark which also noted that accurate

359 classification was challenging to achieve for short complete genomes, i.e., genomes $\leq 5 \mathrm{~kb}$ (Jang 
360 et al., 2019). Hence, short fragments $(<10 \mathrm{~kb})$ may not be informative enough in terms of gene

361 content to be robustly placed in a gene-sharing network and may artificially form 'new' virus

362 clusters.

363 Currently, beyond vContact2, most viral classification tools such as VIRIDIC and VipTree

364 have also been optimized to classify full viral genomes (Nishimura et al., 2017b; Moraru,

365 Varsani \& Kropinski, 2020). We thus sought to evaluate whether this decrease in performance

366 with short fragments was a specificity of gene-sharing networks or was also observed for other

367 taxonomic classification approaches. To test this, we performed similar comparisons of

368 taxonomic assignment for varying genome fragment lengths using other viral classification tools

369 including VipTree (genome-wide similarities-based), VIRIDIC (BLASTN-based), and VPF-

370 class (protein family based). The general results show that the performance of these tools also

371 increased with fragment size (Figure 3B, Figure S6, Figure S8). For VPF-class, the percentage of

372 sequence with a taxonomic assignation increased from $\sim 46 \%$ for $3 \mathrm{kbp}$ fragments to $\sim 82 \%$ for 20

$373 \mathrm{kbp}$ (Figure 3B), while the percentage of sequences assigned to the correct genus also increased

374 with sequence length (Figure S8B). For ViPTree and VIRIDIC, an increase in performance was

375 also observed from $3 \mathrm{kbp}$ through $20 \mathrm{kbp}$ (Figure S8). Together these results suggest genome

376 fragmentation negatively impact virus taxonomic classification for all common approaches, with

377 only longer genome fragments $(\geq 10 \mathrm{kbp})$ providing sufficient information for an accurate and

378 meaningful taxonomy assignment.

379

380

Auxiliary metabolic gene or not, that is the question

381

As sequencing technology and assembly algorithms improve, the increasing genomic

382 context of uncultivated viruses provides an invaluable window into our ability to identify novel

383 virus-encoded auxiliary metabolic genes, or AMGs. Problematically, however, until complete

384 virus genomes are available, robustly identifying metabolically interesting genes in assembled (viruses) sequences from metagenomes remains a challenge for the field (e.g. see re-analyses of past 'AMG' studies in (Roux et al., 2013; Enault et al., 2017)). There are two major challenges in AMG analysis. First, even the most highly purified virus particle metagenome includes some degree of cellular genomic fragments (Roux et al., 2013; Zolfo et al., 2019). Thus, it is critical to demonstrate that any candidate AMG is indeed virus-encoded and not derived from cellular 'contamination', which requires adequate genomic context. Second, standard sequence analysis 
391 cannot always determine whether a candidate AMG is involved in a metabolic pathway or

392 instead associated with 'primary' viral functions such as genome replication or host lysis. Based

393 upon previous (Clokie et al., 2006; Sharon et al., 2007; Dinsdale et al., 2008; Millard et al., 2009;

394 Wommack et al., 2015; Hurwitz, Brum \& Sullivan, 2015; Roux et al., 2016; Breitbart et al.,

395 2018; Roitman et al., 2018; Ahlgren et al., 2019; Gazitúa et al., 2020; Kieft et al., 2020; Mara et

396 al., 2020), we propose guidelines to systematize the evaluation of candidate AMGs including: $(i)$

397 virus identification and quality assessment, (ii) AMG identification, genomic context assessment, 398 and functional annotation, and (iii) further investigation of putative AMGs function (Figure 4).

\section{Virus identification and quality assessment}

401 For AMG studies, we recommend using a combination of tools with strict quality thresholds 402 to identify high-confidence virus sequences (Figure 4, "Viral contigs identification"). For 403 example, high-confidence sequences might be those identified by Virsorter $($ cat 1,2$)$ and 404 VirFinder/DeepVirFinder (score $\geq 0.9, p$-value $<0.05$ ). For length of the contig, while we have in 405 the past used viral contigs $\geq 1.5 \mathrm{kbp}$ for AMG detection (Hurwitz, Hallam \& Sullivan, 2013; 406 Hurwitz, Brum \& Sullivan, 2015; Roux et al., 2016), improved sequencing and assembly 407 capabilities offer the opportunity to be less permissive since smaller contigs increase the risk of 408 false positives. Currently, we recommend increasing the minimum size threshold for AMGs 409 work to $\geq 10 \mathrm{kbp}$, or those that are circular (and thus interpreted to be complete genomes). 410 Complementary to virus identification tools, we recommend using ViromeQC (Zolfo et al., 411 2019) to evaluate virome contamination at the dataset level, and CheckV (Nayfach et al., 2020)

412 to identify and remove host contamination based on gene content for individual sequences.

413 Finally, for cases where integrated prophages are likely assembled in a contig including both a

414 host and a viral region, we recommend using prophage-specialized tools such as PHASTER 415 (Arndt et al., 2017) for more refined prophage/provirus identification and boundary demarcation. 416

417 You are confident you have a virus sequence, but does it include any candidate AMGs?

418 Next, candidate AMGs must be identified within the selected high-confidence viral contigs 419 (Figure 4 "Identification of candidate AMGs"). The key step in this process is to correctly 
420 interpret results from a functional annotation pipeline to distinguish genes involved in host

421 metabolism from genes involved in the viral replication cycle, often based on existing ontologies

422 or manually defined keywords (Breitbart et al., 2018). To further refine this candidate AMG

423 identification, it has been proposed that metabolic genes associated with a KEGG metabolic

424 pathway would constitute "Class I" AMGs (i.e. highest confidence) while metabolic genes not

425 directly included in a metabolic pathway (e.g. transport function) would represent "Class II"

426 AMGs (lower confidence; (Hurwitz, Brum \& Sullivan, 2015)). Importantly, depending on the

427 definition one uses for 'host metabolism' vs 'core viral functions', some genes currently

428 described in the literature as AMGs might not be legitimate AMGs, including some nucleotide-

429 related genes (Kieft, Zhou \& Anantharaman, 2020) or glycosyl transferases and glycoside

430 hydrolases that are often used for surface attachment and entry (Shaffer et al., 2020). We thus

431 recommend researchers to use the utmost caution when analyzing genes for which a true role and

432 function remains uncertain and avoid systematically calling these simply "AMGs" without

433 further qualifiers or caveats.

434 While prior AMG identification has often been done using manual inspection of the contigs

435 functional annotation, there is opportunity now to advance towards a more systematic and semi-

436 scalable approach to identify AMGs, with two new automated tools recently released. DRAM

437 (Distilled and Refined Annotation of Metabolism), which is optimized for microbial annotation,

438 but includes a 'DRAM-v' module for viruses, leverages expert-curated AMG databases for

439 functional annotation and a two-component scoring system to assess the likelihood of a gene

440 being encoded on a virus genome (Shaffer et al., 2020). Meanwhile VIBRANT, which is built

441 for virus identification but also performs functional annotation, automatically curate KEGG-

442 based annotations to highlight candidate AMGs associated to KEGG 'metabolic pathways' and

443 'sulfur relay system' categories (Kieft, Zhou \& Anantharaman, 2020). Both tools thus provide a

444 quick and automated way to obtain a list of candidate AMGs which nevertheless must be further

445 analyzed to $(i)$ verify that the candidate AMG is indeed encoded by a virus, and (ii) verify that

446 the candidate AMG is indeed involved in a cellular metabolic pathway.

448 How do you recognize a candidate AMG that may not actually be virus-encoded? 
Although automated annotation tools such as DRAM-v and VIBRANT are helpful in speeding up the identification of candidate AMG, any detailed ecological or evolutionary analysis of an AMG requires additional manual inspection of both genomic context and

452 predicted functions. Here, we illustrate examples of typical "mistakes" made by automated tools 453 (Figure 4 “Genomic context assessment of candidate AMGs").

454 First, two examples of sequences likely to be genuinely viral, either closely related to a 455 known phage (contig_1, 'likely viral') or not (contig_2, 'possible viral') are presented in Figure 456 4. These sequences are mostly composed of viral or unknown genes, with little to no "cellular457 like" gene outside of the single candidate AMG. Next to these however, are four examples of 458 AMGs predicted yet unlikely to be viral ('unlikely viral' candidates). Contig_3 represents a 459 sequence $\sim 120 \mathrm{kbp}$ with dense, short genes, and no viral/viral-like genes. This sequence is likely 460 to be a cellular genomic region, possibly a mobile genetic element, that could easily be mistaken 461 for a phage by automated tools. Next in contig_4, the candidate AMG is surrounded by genes 462 that reveal little evidence of belonging to a viral genome, but where VirSorter (categories 1 and 463 2) and/or VirFinder (score $\geq 0.9$ and $p$-value $<0.05$ ) suggest the contig overall is of viral origin. 464 Conservatively, these genes AMGs should not be considered further due to the low contextual 465 evidence of the region immediately surrounding the candidate AMG to be of viral origin. Finally, in contig_5, the candidate AMG is at the edge of the viral contig along with a tRNA and a phage

467 integrase. This example likely represents the miscall of a prophage boundary, and the AMG468 containing region is likely a small fraction of the host genome, where metabolic genes are much more common (Table S2). Overall, further examining the specific genomic context around each candidate AMG is highly recommended in order to identify false-positive detections, i.e. nonviral sequences wrongly considered as viral by automated tools. This is especially critical in

472 AMG analysis because these non-viral regions, while overall rare among the entire set of 473 sequences predicted as viral, will typically have a much higher probability of including genes 474 annotated as metabolic, i.e. candidate "AMGs". Hence, even a small number of contaminating 475 sequences can substantially impact downstream AMG analyses. 
As for their viral origin (see above), the predicted function of candidate AMGs will typically need to be refined beyond the results of automated functional annotation pipelines. While the ideal proof of function is through biochemical assay of the AMGs to support the in silico inferred function, this is laborious and time-consuming lab work, such that only a handful of AMGs known to date has been experimentally validated -- psbA (Lindell et al., 2005; Clokie et al., 2006), pebS (Dammeyer et al., 2008), and glycoside hydrolase (Emerson et al., 2018). To provide scalable in silico evaluation of putative AMGs and guide future experimental validation, we recommend the following analyses (Figure 4 "AMG functional analysis").

First, deeper functional analyses should be conducted to assess, where possible, whether the AMG contains known conserved residues and active sites, as well as whether structural predictions are consistent with the sequence-based functional prediction (Figure 4). The analysis of protein conserved regions and active sites can be done manually via inspection of sequence alignments, as well as semi-automatedly where possible using, e.g. PROSITE (Sigrist et al., 2013) and HHPred (Zimmermann et al., 2018). For protein structural predictions there are several available tools including Phyre $^{2}$ (Kelly et al., 2015), SWISS-MODEL (Waterhouse et al., 2018), and I-TASSER (Yang \& Zhang, 2015). Protein structure is known to be more conserved than primary protein sequence, thus enabling the annotation of more divergent proteins, as well as supporting other functional annotation pipelines (Kelly et al., 2015). Importantly, when interpreting results of predicted structures and structure-based similarity for candidate AMGs, one should verify that the predicted structure is consistent with the predicted biological function, 498 but also consider the relationship between top hits, in which one would expect to have several of 499 the top hits homologous to each other (Roux et al., 2016; Gazitúa et al., 2020). The latest recommended cut-offs for these functional annotation tools are provided in Table 2.

501 Evolutionary analyses can be used to assess whether selection appears to be acting on the 502 viral gene homolog. For instance, the ratio of non-synonymous $(p \mathrm{~N})$ to synonymous 503 polymorphisms $(p \mathrm{~S})$-- known as $p \mathrm{~N} / p \mathrm{~S}$-- can be used to evaluate whether the candidate AMGs 504 is under purifying selection as would be expected for a functional gene (Schloissnig et al., 2013; 505 Roux et al., 2016). Pragmatically, $p \mathrm{~N} / p \mathrm{~S}$ values can be calculated manually using tools designed 
506 specifically for analyzing micro- and macro-diversity in metagenomes (e.g. MetaPop (Gregory et

507 al., 2020a)).

508

509 Your AMG appears viral and predicted to be functional and involved in host cell metabolism,

510 what is its ecological and evolutionary story to tell?

511 Until this point, the candidate AMGs have gone through a series of meticulous vetting steps

512 resulting in putative AMGs that can be used for downstream analyses such as phylogeny,

513 ecological analysis, and experimental functional assays. We provide recommendations for each

514 as follows (Figure 4 "Additional (optional) analysis of the putative AMGs").

515 To assess the evolutionary history of AMGs, phylogenetic analysis is carried out on individual

516 AMGs and their corresponding microbial homologs. Briefly, for each AMG, one first needs to

517 obtain homologs via sequence similarity searches (e.g. BLAST vs an appropriate database), then

518 do multiple sequence alignments (e.g. MAFFT (Katoh et al., 2002)), assess for intragenic

519 recombination (e.g. RDP4 software (Martin et al., 2015)), build phylogenetic trees (e.g. IQ-TREE

520 (Nguyen et al., 2015)), and visualize them (e.g. iTOL, (Letunic \& Bork, 2019)). With these data

521 in-hand, each phylogenetic tree can be examined to determine the number of transfer events that

522 have occurred between microbes and viruses, as well as the 'origin' of the AMGs within the

523 cellular and viral sequences in the analyses (sensu Sullivan et al., (2010)).

524 Bona fide AMGs also typically have an ecological story to tell. Currently, the abundance of

525 AMGs is estimated by read mapping against the viral populations that contain those AMGs

526 (Gazitúa et al., 2020). However, a more sophisticated approach, where possible, would be to use

527 the evolutionary inferences and multiple sequence alignments to identify virus-specific

528 'signatures' in the sequences that could be read-mapped to differentiate viral from cellular

529 contributions to the gene, transcript, or protein pool in any given natural community. While such

530 analyses are quite rare, e.g. (Sharon et al., 2007; Tzahor et al., 2009) growing AMG datasets

531 should empower researchers to address this question of the virus 'AMG' contributions. Further,

532 as virus-host prediction capabilities improve (Edwards et al., 2016; Villarroel et al., 2016; Galiez

533 et al., 2017; Emerson et al., 2018; Wang et al., 2020), there is opportunity to combine these with

534 AMG predictions to build understanding of ecologically-critical nuances of virus-host 
535 interactions. Finally, viral AMGs are under very different selective pressures than their host

536 homologues given their viro-centric roles during infection. Will functional validation reveal viral

537 versions that are fundamentally different? On one side, we may expect viral AMGs to have

538 subtle mutations that might impact their enzyme efficiency (e.g. mutations in the PEST domain

539 of PsbA (Sharon et al., 2007)) or substrate preferences (e.g. (Enav et al., 2018)). On the other

540 side, we may expect viruses to encode more efficient proteins with "new" functions. An example

541 here is cyanophage-encoded 'PebA', which was thought to be a divergent 15,16-

542 dihydrobiliverdin: ferredoxin oxidoreductase ( $p e b \mathrm{~A}$ ), but experimentally was shown to combine

543 the capabilities of two host enzymes, PebA and PebB, to directly convert biliverdin IXX $\alpha$ to

544 phycoerythrobilin and was thus renamed to PebS, a phycoerythrobilin synthase (Dammeyer et

545 al., 2008).

546 Together, we hope these guidelines provide best-practice standard operating procedures for

547 scientists to identify and evaluate candidate AMGs, as well as an emerging roadmap for how best

548 to robustly bring this more nuanced and under-studied component of virus-host interactions to

549 light so that viruses can be better incorporated into ecosystem models.

550

\section{Conclusions}

552 While viromics has proven invaluable for revealing the roles of viruses across diverse

553 ecosystems, the emergent field of viral ecogenomics is in a state of rapid flux, experimentally

554 and analytically. Here, we add to recent best practices efforts by evaluating and providing

555 benchmarking for identifying and classifying viruses from viral-particle-enriched and bulk

556 metagenomes, as well as recommendations for best practices for studying virus-encoded

557 auxiliary metabolic genes. These efforts addressed some critical issues in standard operating

558 procedures for viral ecogenomics researchers. Similar efforts will be needed to establish best

559 practices in studying new emerging types of analysis and data including micro-diversity of virus

560 populations (Gregory et al., 2019), and long-read sequencing (Warwick-Dugdale et al., 2018;

561 Zablocki et al., 2021). Further, technological and analytical opportunities are being developed to

562 better capture ssDNA and RNA viruses, as well as to establish dsDNA viral activity 
563 (Moniruzzaman et al., 2017; Emerson et al., 2018; Roux et al., 2019; Sommers et al., 2019; Starr 564 et al., 2019; Trubl et al., 2019; Callanan et al., 2020). Finally, though viral discovery is now

565 performed tens to hundreds of thousands of viruses at a time, the ability to link these new viruses

566 to their hosts is still limited. Improved in silico approaches, such as those based on BLAST

567 similarity, $k$-mers (such as WIsH (Galiez et al., 2017), and HostPhinder (Villarroel et al., 2016)),

568 oligonucleotide frequency (VirHostMatcher (Wang et al., 2020)), and CRISPR-Cas (Paez-Espino

569 et al., 2016) have been recently proposed to predict the potential hosts of uncultivated viruses,

570 which still need to be thoroughly tested and benchmarked across a variety of dataset types and

571 sizes. Moreover, predictions from these in silico prediction tools need to be complemented with

572 robustly benchmarked, high-throughput experimental methods, e.g. epicPCR, viral tagging, Hi-C

573 (Deng et al., 2014; Bickhart et al., 2019; Yaffe \& Relman, 2020; Sakowski et al., 2021) to

574 validate these predictions.

575

576

577

\section{Acknowledgements:}

578 We would like to thank Drs. Heather Maughan and Chistine Sun for comments on the structure of an early draft of the manuscript, Drs. Ho Bin Jang and Olivier Zablocki, as well as

580 Mohamed M. Mohamed, and Funing Tian for the many constructive discussions.

581

582 Abbreviations:

583 MCC: Matthews's correlation coefficient,

584 Sn: clustering-wise sensitivity,

585 PPV: the positive predictive value,

586 Acc: accuracy,

$587 \mathrm{Sep}_{c o}$ : complex (ICTV taxonomy)-wise separation,

$588 \mathrm{Sep}_{c l}$ : cluster-wise separation, and

589 Sep: clustering-wise separation.

590

591 Funding: 
592 Funding was provided by NSF (\#OCE1829831, \#ABI1758974), the U.S. Department of Energy

593 (\#DE-SC0020173 and \#248445), and the Gordon and Betty Moore Foundation (\#3790) to MBS.

594 The work conducted by the U.S. Department of Energy Joint Genome Institute is supported by

595 the Office of Science of the U.S. Department of Energy under contract no. DE-AC02-

596 05CH11231. An award from the Ohio Supercomputer Center (OSC) to MBS supported

597 computing resources used here.

598

599 Grant Disclosures:

600 - NSF (\#OCE1829831, \#ABI1758974).

601 - The U.S. Department of Energy \#DE-SC0020173 and \#248445, and \# DE-AC02-

$60205 \mathrm{CH} 11231$.

603 - The Gordon and Betty Moore Foundation (\#3790).

604 - The Ohio Supercomputer Center (OSC).

605

606 Ethics approval and consent to participate

607 Not applicable

608

609 Conflict of interest:

610 Maria Consuelo Gazitua is a founder and CEO of Viromica Consulting, Chile.

611 All the authors declare that they have no competing interests.

612

613 Authors' Contributions:

614 - Akbar Adjie Pratama conceived and designed the experiments, prepare the simulated

615 datasets, performed the experiments, analyzed the data, prepared the manuscript, prepared

616 figures and/or tables.

617 - Ben Bolduc, Ahmed A. Zayed, conceived the study, and provided the scripts, analyzed the 618 data.

619 - Zhi-Ping Zhong, Jiarong Guo, performed the viral identification analysis.

620 - Dean Vik, M. Consuelo Gazitúa, James Wainaina, prepared specific sections of the 621 manuscript. 
622 - Simon Roux \& Matthew B. Sullivan conceived and designed the experiments, prepared the 623 manuscript.

624 - All authors helped write and edit the manuscript and approved the final draft.

625

626 Availability of data and materials:

627 - All sequencing data used to simulate datasets is publicly available and was obtained from

628 NCBI: $(i)$ Viral RefSeq v.203 for viral sequences

629 (https://www.ncbi.nlm.nih.gov/genome/viruses/), (ii) Bacteria RefSeq v.203

630 (https://www.ncbi.nlm.nih.gov/refseq/ (iii) archaea RefSeq v.203

631 (https://www.ncbi.nlm.nih.gov/refseq/) (iv) plasmids RefSeq v.203

632 (https://www.ncbi.nlm.nih.gov/refseq/) and (v) human GRCh38 for eukaryote (accession

633 number GCA_000001405.15). The 142 cyanophages' genomes are available in the GenBank

634 repository under the accession numbers KJ019026- KJ019131, KJ019134- KJ019165,

635 JN371768, and KF156338-40.

636 - The scripts used for virus identification, classification, mock communities' datasets, virus

637 datasets, vConTACT v2 input and AMG input files have been uploaded to

638 https://bitbucket.org/MAVERICLab/standard_viromics2/

639

640 Supplementary information:

641 Supplementary table 1. Virus genomes used in this study; Supplementary table 2. AMGs

642 annotation table; Supplementary figure 1. Additional metrics for viral identification across

643 datasets; Supplementary figure 2. Results from the viral identification analysis for VIBRANT

644 with no virome flag; Supplementary figure 3. False-discovery rate of viral sequence

645 identification tools when challenged with Archaea, Eukaryote and Plasmid datasets;

646 Supplementary figure 4. Pairwise analyses of the combined viral identification tools efficiency 647 parameters for varying genome sizes; Supplementary figure 5. Gene-sharing network topology 648 and performances; Supplementary figure 6. Percentage of 'correct' genus-assignments;

649 Supplementary figure 7. Comparison of the performances of viral gene-sharing network-based 650 classification, vConTACT v2 across fragment size; Supplementary figure 8. Performance

651 evaluation of VipTree and VIRIDIC across fragment sizes.

652 


\section{References:}

654

655

656

657

658

659

660

661

662

663

664

665

666

667

668

669

670

671

672

673

674

675

676

677

678

679

680

681

682

683

684

685

686

687

688

689

690

691

692

693

694

695

696

697

698
Adriaenssens EM, Van Zyl L, De Maayer P, Rubagotti E, Rybicki E, Tuffin M, Cowan DA. 2015. Metagenomic analysis of the viral community in Namib Desert hypoliths. Environmental Microbiology 17:480-495. DOI: 10.1111/1462-2920.12528.

Ahlgren NA, Fuchsman CA, Rocap G, Fuhrman JA. 2019. Discovery of several novel, widespread, and ecologically distinct marine Thaumarchaeota viruses that encode amoC nitrification genes. ISME Journal 13:618-631. DOI: 10.1038/s41396-018-0289-4.

Aiemjoy K, Altan E, Aragie S, Fry DM, Phan TG, Deng X, Chanyalew M, Tadesse Z, Callahan EK, Delwart E, Keenan JD. 2019. Viral species richness and composition in young children with loose or watery stool in Ethiopia. BMC Infectious Diseases 19:1-10. DOI: 10.1186/s12879-019-3674-3.

Amgarten D, Braga LPP, da Silva AM, Setubal JC. 2018. MARVEL, a tool for prediction of bacteriophage sequences in metagenomic bins. Frontiers in Genetics 9:1-8. DOI: 10.3389/fgene.2018.00304.

Anantharaman K, Duhaime MB, Breier JA, Wendt K, Brandy M. Toner, Dick GJ. 2014. Abundance of viruses in deep oceanic waters. Science 344:757-760. DOI: $10.1126 /$ science. 1252229.

Arndt D, Marcu A, Liang Y, Wishart DS. 2017. PHAST, PHASTER and PHASTEST: Tools for finding prophage in bacterial genomes. Briefings in Bioinformatics:1-8. DOI: 10.1093/bib/bbx121.

Bäckström D, Yutin N, Jørgensen SL, Dharamshi J, Homa F, Zaremba-Niedwiedzka K, Spang A, Wolf YI, Koonin E V., Ettema TJG. 2019. Virus Genomes from Deep Sea Sediments Expand the Ocean Megavirome and Support Independent Origins of Viral Gigantism. mBio 10:e2497-18. DOI: 10.1128/MBIO.02497-18.

Bickhart DM, Watson M, Koren S, Panke-Buisse K, Cersosimo LM, Press MO, Van Tassell CP, Van Kessel JAS, Haley BJ, Kim SW, Heiner C, Suen G, Bakshy K, Liachko I, Sullivan ST, Myer PR, Ghurye J, Pop M, Weimer PJ, Phillippy AM, Smith TPL. 2019. Assignment of virus and antimicrobial resistance genes to microbial hosts in a complex microbial community by combined long-read assembly and proximity ligation. Genome Biology 20:118. DOI: 10.1186/s13059-019-1760-x.

Blanc-Mathieu R, Kaneko H, Endo H, Chaffron S, Hernández-Velázquez R, Nguyen CH, Mamitsuka H, Henry N, Vargas C de, Sullivan MB, Suttle CA, Guidi L, Ogata H. 2019. Viruses of the eukaryotic plankton are predicted to increase carbon export efficiency in the global sunlit ocean. bioRxiv. DOI: 10.1101/710228.

Breitbart M, Bonnain C, Malki K, Sawaya NA. 2018. Phage puppet masters of the marine microbial realm. Nature Microbiology 3:754-766. DOI: 10.1038/s41564-018-0166-y.

Breitbart M, Thompson L, Suttle C, Sullivan M. 2007. Exploring the Vast Diversity of Marine Viruses. Oceanography 20:135-139. DOI: 10.5670/oceanog.2007.58.

Brum JR, Ignacio-espinoza JC, Roux S, Doulcier G, Acinas SG, Alberti A, Chaffron S. 2015. Patterns and ecological drivers of ocean viral communities. Science 348:1261498-1-11. DOI: $10.1126 /$ science.1261498.

Callanan J, Stockdale SR, Shkoporov A, Draper LA, Ross RP, Hill C. 2020. Expansion of known ssRNA phage genomes: From tens to over a thousand. Science Advances 6. DOI: 10.1126/sciadv.aay5981.

Chicco D, Jurman G. 2020. The advantages of the Matthews correlation coefficient (MCC) over F1 score and accuracy in binary classification evaluation. BMC Genomics 21:1-13. DOI:

PeerJ reviewing PDF | (2020:11:55638:2:0:NEW 20 Apr 2021) 
699

700

701

702

703

704

705

706

707

708

709

710

711

712

713

714

715

716

717

718

719

720

721

722

723

724

725

726

727

728

729

730

731

732

733

734

735

736

737

738

739

740

741

742

743

744

10.1186/s12864-019-6413-7.

Clokie MRJ, Shan J, Bailey S, Jia Y, Krisch HM, West S, Mann NH. 2006. Transcription of a "photosynthetic" T4-type phage during infection of a marine cyanobacterium.

Environmental Microbiology 8:827-835. DOI: 10.1111/j.1462-2920.2005.00969.x.

Clooney AG, Sutton TDS, Shkoporov AN, Plevy SE, Ross RP, Hill C, Clooney AG, Sutton TDS, Shkoporov AN, Holohan RK, Daly KM, Regan OO. 2019. Whole-virome analysis sheds light on viral dark matter in inflammatory bowel disease. Cell Host and Microbe:115. DOI: 10.1016/j.chom.2019.10.009.

Conceição-Neto N, Zeller M, Lefrère H, De Bruyn P, Beller L, Deboutte W, Yinda CK, Lavigne R, Maes P, Ranst M Van, Heylen E, Matthijnssens J. 2015. Modular approach to customise sample preparation procedures for viral metagenomics: A reproducible protocol for virome analysis. Scientific Reports 5:1-14. DOI: 10.1038/srep16532.

Coutinho FH, Silveira CB, Gregoracci GB, Thompson CC, Edwards RA, Brussaard CPD, Dutilh BE, Thompson FL. 2017. Marine viruses discovered via metagenomics shed light on viral strategies throughout the oceans. Nature Communications 8:15955. DOI: 10.1038/ncomms 15955 .

Dammeyer T, Bagby SC, Sullivan MB, Chisholm SW, Frankenberg-Dinkel N. 2008. Efficient Phage-Mediated Pigment Biosynthesis in Oceanic Cyanobacteria. Current Biology 18:442448. DOI: 10.1016/j.cub.2008.02.067.

Deng L, Ignacio-Espinoza JC, Gregory AC, Poulos BT, Weitz JS, Hugenholtz P, Sullivan MB. 2014. Viral tagging reveals discrete populations in Synechococcus viral genome sequence space. Nature 513:242-245. DOI: 10.1038/nature13459.

Dinsdale EA, Edwards RA, Hall D, Angly F, Breitbart M, Brulc JM, Furlan M, Desnues C, Haynes M, Li L, McDaniel L, Moran MA, Nelson KE, Nilsson C, Olson R, Paul J, Brito BR, Ruan Y, Swan BK, Stevens R, Valentine DL, Thurber RV, Wegley L, White BA, Rohwer F. 2008. Functional metagenomic profiling of nine biomes. Nature 452:629-632. DOI: $10.1038 /$ nature06810.

Duhaime MB, Deng L, Poulos BT, Sullivan MB. 2012. Towards quantitative metagenomics of wild viruses and other ultra-low concentration DNA samples: A rigorous assessment and optimization of the linker amplification method. Environmental Microbiology 14:25262537. DOI: 10.1111/j.1462-2920.2012.02791.x.

Dutilh BE, Reyes A, Hall RJ, Whiteson KL. 2017. Virus Discovery by Metagenomics: The (Im)possibilities. DOI: 10.3389/978-2-88945-308-5.

Edwards RA, McNair K, Faust K, Raes J, Dutilh BE. 2016. Computational approaches to predict bacteriophage-host relationships. FEMS Microbiology Reviews 40:258-272. DOI: 10.1093/femsre/fuv048.

Emerson JB, Roux S, Brum JR, Bolduc B, Woodcroft B., Jang HB, Singleton CM, Solden LM, Naas AE, Boyd JA, Hodgkins SB, Wilson RM, Trubl G, Li C, Frolking S, Pope PB, Wrighton KC, Crill PM, Chanton JP, Sullivan MB. 2018. Host-linked soil viral ecology along a permafrost thaw gradient. Nature Microbiology 3:870-880. DOI: 10.1038/s41564018-0190-y.

Enault F, Briet A, Bouteille L, Roux S, Sullivan MB, Petit MA. 2017. Phages rarely encode antibiotic resistance genes: A cautionary tale for virome analyses. ISME Journal 11:237247. DOI: 10.1038/ismej.2016.90.

Enav H, Kirzner S, Lindell D, Mandel-Gutfreund Y, Beja O. 2018. Adaptation to sub-optimal hosts is a driver of viral diversification in the ocean. bioRxiv:261479. DOI: $10.1101 / 261479$.

Peer) reviewing PDF | (2020:11:55638:2:0:NEW 20 Apr 2021) 
745

752

753

754

755

756

757

758

759

760

761

762

763

764

765

766

767

768

769

770

771

772

773

774

775

776

777

778

779

780

781

782

783

784

785

786

787

788

789

790

Fernandes MA, Verstraete SG, Phan T, Deng X, Stekol E, Lamere B, Lynch S V., Heyman MB, Delwart E. 2019. Enteric Virome and Bacterial Microbiota in Children with Ulcerative Colitis and Crohn Disease. Journal of Pediatric Gastroenterology and Nutrition 68:30-36. DOI: 10.1097/MPG.0000000000002140.

Fuhrman JA. 1999. Marine viruses and their biogeochemical and ecological effects. Nature 399:541-548. DOI: 10.1038/21119.

Galiez C, Siebert M, Enault F, Vincent J, Söding J. 2017. WIsH: who is the host? Predicting prokaryotic hosts from metagenomic phage contigs. Bioinformatics 33:3113-3114. DOI: 10.1093/bioinformatics/btx383.

Gazitúa MC, Vik DR, Roux S, Gregory AC, Bolduc B, Widner B, Mulholland MR, Hallam SJ, Ulloa O, Sullivan MB, Sullivan MB. 2020. Potential virus-mediated nitrogen cycling in oxygen-depleted oceanic waters. The ISME Journal. DOI: 10.1038/s41396-020-00825-6.

Gregory AC, Gerhardt K, Zhong Z-P, Bolduc B, Temperton B, Konstantinidis KT, Sullivan MB. 2020a. MetaPop: A pipeline for macro- and micro-diversity analyses and visualization of microbial and viral metagenome-derived populations. bioRxiv. DOI:

10.1101/2020.11.01.363960.

Gregory AC, Solonenko SA, Ignacio-Espinoza JC, LaButti K, Copeland A, Sudek S, Maitland A, Chittick L, Santos F dos, Weitz JS, Worden AZ, Woyke T, Sullivan MB. 2016. Genomic differentiation among wild cyanophages despite widespread horizontal gene transfer. $B M C$ Genomics 17:930. DOI: 10.1186/s12864-016-3286-x.

Gregory AC, Zablocki O, Zayed AA, Howell A, Bolduc B, Sullivan MB, Gregory AC, Zablocki O, Zayed AA, Howell A, Bolduc B. 2020b. The Gut Virome Database Reveals AgeDependent Patterns of Virome Diversity in the Human Gut Resource The Gut Virome Database Reveals Age-Dependent Patterns of Virome Diversity in the Human Gut. Cell Host and Microbe:1-17. DOI: 10.1016/j.chom.2020.08.003.

Gregory AC, Zayed AA, Sunagawa S, Wincker P, Sullivan MB, Ferland J, Kandels S, Liu Y, Marec C, Vik D. 2019. Marine DNA Viral Macro- and Microdiversity from Pole to Pole. cell:1-15. DOI: 10.1016/j.cell.2019.03.040.

Guidi L, Chaffron S, Bittner L, Eveillard D, Larhlimi A, Roux S, Darzi Y, Audic S, Berline L, Brum JR, Coelho LP, Espinoza JCI, Malviya S, Sunagawa S, Dimier C, Kandels-Lewis S, Picheral M, Poulain J, Searson S, Stemmann L, Not F, Hingamp P, Speich S, Follows M, Karp-Boss L, Boss E, Ogata H, Pesant S, Weissenbach J, Wincker P, Acinas SG, Bork P, De Vargas C, Iudicone D, Sullivan MB, Raes J, Karsenti E, Bowler C, Gorsky G. 2016. Plankton networks driving carbon export in the oligotrophic ocean. Nature 532:465-470. DOI: $10.1038 /$ nature 16942.

Haro-Moreno JM, Rodriguez-Valera F, López-Pérez M. 2019. Prokaryotic Population Dynamics and Viral Predation in a Marine Succession Experiment Using Metagenomics. Frontiers in Microbiology 10:1-14. DOI: 10.3389/fmicb.2019.02926.

Howard-Varona C, Lindback MM, Bastien GE, Solonenko N, Zayed AA, Jang H, Andreopoulos B, Brewer HM, Rio TG del, Adkins JN, Paul S, Sullivan MB, Duhaime MB, Received: 2020. Phage-specific metabolic reprogramming of virocells. Isme J. DOI: 10.1038/s41396019-0580-z.

Hurwitz BL, Brum JR, Sullivan MB. 2015. Depth-stratified functional and taxonomic niche specialization in the 'core' and 'flexible' Pacific Ocean Virome. The ISME Journal 9:472484. DOI: 10.1038/ismej.2014.143.

Hurwitz BL, Deng L, Poulos BT, Sullivan MB. 2013. Evaluation of methods to concentrate and 
791

792

793

794

795

796

797

798

799

800

801

802

803

804

805

806

807

808

809

810

811

812

813

814

815

816

817

818

819

820

821

822

823

824

825

826

827

828

829

830

831

832

833

834

835

836

purify ocean virus communities through comparative, replicated metagenomics. Environmental Microbiology 15:1428-1440. DOI: 10.1111/j.1462-2920.2012.02836.x. Hurwitz BL, Hallam SJ, Sullivan MB. 2013. Metabolic reprogramming by viruses in the sunlit and dark ocean. Genome Biology 14. DOI: 10.1186/gb-2013-14-11-r123.

Ignacio-espinoza JC, Ahlgren NA, Fuhrman JA. 2019. Long-term stability and Red Queen-like strain dynamics in marine viruses. Nature Microbiology. DOI: 10.1038/s41564-019-0628-X.

Jang H Bin, Bolduc B, Zablocki O, Kuhn JH, Roux S, Adriaenssens EM, Brister JR, Kropinski AM, Krupovic M, Lavigne R, Turner D, Sullivan MB. 2019. Taxonomic assignment of uncultivated prokaryotic virus genomes is enabled by gene- sharing networks. Nature Biotechnology 37:632. DOI: 10.1038/s41587-019-0100-8.

Jin M, Guo X, Zhang R, Qu W, Gao B, Zeng R. 2019. Diversities and potential biogeochemical impacts of mangrove soil viruses. Microbiome:1-15.

Jurtz VI, Villarroel J, Lund O, Voldby Larsen M, Nielsen M. 2016. MetaPhinder - Identifying bacteriophage sequences in metagenomic data sets. PLOS ONE 11:1-14. DOI: 10.1371/journal.pone.0163111.

Katoh K, Misawa K, Kuma K, Miyata T. 2002. MAFFT: a novel method for rapid multiple sequence alignment based on fast Fourier transform. Nucleic acids research 30:3059-3066. DOI: $10.1093 / \mathrm{nar} / \mathrm{gkf} 436$.

Kelly LA, Mezulis S, Yates C, Wass M, Sternberg M. 2015. The Phyre2 web portal for protein modelling, prediction, and analysis. Nature Protocols 10:845-858. DOI: 10.1038/nprot.2015-053.

Kieft K, Zhou Z, Anantharaman K. 2020. VIBRANT: automated recovery, annotation and curation of microbial viruses, and evaluation of viral community function from genomic sequences. Microbiome 8:90. DOI: 10.1186/s40168-020-00867-0.

Kieft K, Zhou Z, Anderson RE, Buchan A, Campbell BJ, Hallam SJ, Hess M, Sullivan MB, Walsh DA, Roux S, Anantharaman K. 2020. Ecology of inorganic sulfur auxiliary metabolism in widespread bacteriophages. bioRxiv. DOI: 10.1017/CBO9781107415324.004.

Laber CP, Hunter JE, Carvalho F, Collins JR, Hunter EJ, Schieler BM, Boss E, More K, Frada M, Thamatrakoln K, Brown CM, Haramaty L, Ossolinski J, Fredricks H, Nissimov JI, Vandzura R, Sheyn U, Lehahn Y, Chant RJ, Martins AM, Coolen MJL, Vardi A, Ditullio GR, Van Mooy BAS, Bidle KD. 2018. Coccolithovirus facilitation of carbon export in the North Atlantic. Nature Microbiology 3:537-547. DOI: 10.1038/s41564-018-0128-4.

Lara E, Vaqué D, Sà EL, Boras JA, Gomes A, Borrull E, Díez-Vives C, Teira E, Pernice MC, Garcia FC, Forn I, Castillo YM, Peiró A, Salazar G, Morán XAG, Massana R, Catalá TS, Luna GM, Agustí S, Estrada M, Gasol JM, Duarte CM. 2017. Unveiling the role and life strategies of viruses from the surface to the dark ocean. Science Advances 3. DOI: 10.1126/sciadv. 1602565.

Letunic I, Bork P. 2019. Interactive Tree Of Life (iTOL) v4: recent updates and new developments. Nucleic Acids Research:1-4. DOI: 10.1093/nar/gkz239.

Li Y, Liu H, Pan H, Zhu X, Liu C, Zhang Q, Luo Y, Di H, Xu J. 2019. T4-type viruses: Important impacts on shaping bacterial community along a chronosequence of 2000-year old paddy soils. Soil Biology and Biochemistry 128:89-99. DOI: 10.1016/j.soilbio.2018.10.007.

Lim ES, Zhou Y, Zhao G, Bauer IK, Droit L, Ndao IM, Warner BB, Tarr PI, Wang D, Holtz LR. 2015. Early life dynamics of the human gut virome and bacterial microbiome in infants. 
837

838

839

840

841

842

843

844

845

846

847

848

849

850

851

852

853

854

855

856

857

858

859

860

861

862

863

864

865

866

867

868

869

870

871

872

873

874

875

876

877

878

879

880

881

882

Nature Medicine 21:1228-1234. DOI: 10.1038/nm.3950.

Lindell D, Jaffe JD, Coleman ML, Futschik ME, Axmann IM, Rector T, Kettler G, Sullivan MB, Steen R, Hess WR, Church GM, Chisholm SW. 2007. Genome-wide expression dynamics of a marine virus and host reveal features of co-evolution. Nature 449:83-86. DOI: 10.1038 /nature 06130 .

Lindell D, Jaffe JD, Johnson ZI, Church GM, Chisholm SW. 2005. Photosynthesis genes in marine viruses yield proteins during host infection. Nature 438:86-89. DOI: 10.1038/nature04111.

Luo E, Eppley JM, Romano AE, Mende DR, DeLong EF. 2020. Double-stranded DNA virioplankton dynamics and reproductive strategies in the oligotrophic open ocean water column. The ISME journal. DOI: 10.1038/s41396-020-0604-8.

Macke TJ, Ecker DJ, Gutell RR, Gautheret D, Case DA, Sampath R. 2001. RNAMotif, an RNA secondary structure definition and search algorithm. Nucleic Acids Research 29:4724-4735. DOI: $10.1093 / \mathrm{nar} / 29.22 .4724$.

Mann NH, Cook A, Millard A, Bailey S, Clokie M. 2003. Bacterial photosynthesis genes in a virus. Nature 424:741. DOI: 10.1038/424741a.

Mara P, Vik D, Pachiadaki MG, Suter EA, Taylor GT, Sullivan MB, Edgcomb VP. 2020. Viral elements and their potential influence on microbial processes along the permanently stratified Cariaco Basin redoxcline. The ISME Journal. DOI: 10.1038/s41396-020-00739-3.

Martin DP, Murrell B, Golden M, Khoosal A, Muhire B. 2015. RDP4: Detection and analysis of recombination patterns in virus genomes. Virus Evolution 1:1-5. DOI: 10.1093/ve/vev003.

Millard AD, Zwirglmaier K, Downey MJ, Mann NH, Scanlan DJ. 2009. Comparative genomics of marine cyanomyoviruses reveals the widespread occurrence of Synechococcus host genes localized to a hyperplastic region: Implications for mechanisms of cyanophage evolution. Environmental Microbiology 11:2370-2387. DOI: 10.1111/j.14622920.2009.01966.x.

Mizuno CM, Rodriguez-Valera F, Kimes NE, Ghai R. 2013. Expanding the Marine Virosphere Using Metagenomics. PLoS Genetics 9. DOI: 10.1371/journal.pgen.1003987.

Moniruzzaman M, Wurch LL, Alexander H, Dyhrman ST, Gobler CJ, Wilhelm SW. 2017. Virus-host relationships of marine single-celled eukaryotes resolved from metatranscriptomics. Nature Communications 8:1-10. DOI: 10.1038/ncomms16054.

Moraru C, Varsani A, Kropinski AM. 2020. VIRIDIC - A Novel Tool to Calculate the Intergenomic Similarities of. Viruses 12:1268. DOI: 10.3390/v12111268.

Nayfach S, Camargo AP, Eloe-fadrosh E, Roux S, Kyrpides N, Berkeley L. 2020. CheckV: assessing the quality of metagenome-assembled viral genomes. bioRxiv.

Nguyen LT, Schmidt HA, Von Haeseler A, Minh BQ. 2015. IQ-TREE: A fast and effective stochastic algorithm for estimating maximum-likelihood phylogenies. Molecular Biology and Evolution 32:268-274. DOI: 10.1093/molbev/msu300.

Nishimura Y, Watai H, Honda T, Mihara T, Omae K, Roux S, Blanc-Mathieu R, Yamamoto K, Hingamp P, Sako Y, Sullivan MB, Goto S, Ogata H, Yoshida T. 2017a. Environmental Viral Genomes Shed New Light on Virus-Host Interactions in the Ocean. American society for microbiology 2.

Nishimura Y, Yoshida T, Kuronishi M, Uehara H, Ogata H, Goto S. 2017b. ViPTree: The viral proteomic tree server. Bioinformatics 33:2379-2380. DOI: 10.1093/bioinformatics/btx157. Norman JM, Handley SA, Baldridge MT, Droit L, Liu CY, Keller BC, Kambal A, Monaco CL, Zhao G, Fleshner P, Stappenbeck TS, McGovern DPB, Keshavarzian A, Mutlu EA, Sauk J, 
883

884

885

886

887

888

889

890

891

892

893

894

895

896

897

898

899

900

901

902

903

904

905

906

907

908

909

910

911

912

913

914

915

916

917

918

919

920

921

922

923

924

925

926

927

928

Gevers D, Xavier RJ, Wang D, Parkes M, Virgin HW. 2015. Disease-specific alterations in the enteric virome in inflammatory bowel disease. Cell 160:447-460. DOI:

10.1016/j.cell.2015.01.002.

Paez-Espino D, Eloe-Fadrosh EA, Pavlopoulos GA, Thomas AD, Huntemann M, Mikhailova N, Rubin E, Ivanova NN, Kyrpides NC. 2016. Uncovering Earth's virome. Nature 536:425430. DOI: 10.1038/nature19094.

Paez-Espino D, Pavlopoulos GA, Ivanova NN, Kyrpides NC. 2017. Nontargeted virus sequence discovery pipeline and virus clustering for metagenomic data. Nature Protocols 12:16731682. DOI: $10.1038 /$ nprot.2017.063.

Pons JC, Paez-Espino D, Riera G, Ivanova N, Kyrpides NC, Llabrés M. 2021. VPF-Class: Taxonomic assignment and host prediction of uncultivated viruses based on viral protein families. Bioinformatics:1-9.

Ponsero AJ, Hurwitz BL. 2019. The Promises and Pitfalls of Machine Learning for Detecting Viruses in Aquatic Metagenomes. Frontiers in Microbiology 10:1-6. DOI: 10.3389/fmicb.2019.00806.

Ren J, Song K, Deng C, Ahlgren NA, Fuhrman JA, Li Y, Xie X, Sun F. 2019. Identifying viruses from metagenomic data by deep learning. Quantitative Biology.

Reyes A, Blanton L V., Cao S, Zhao G, Manary M, Trehan I, Smith MI, Wang D, Virgin HW, Rohwer F, Gordon JI. 2015. Gut DNA viromes of Malawian twins discordant for severe acute malnutrition. Proceedings of the National Academy of Sciences 112:11941-11946. DOI: $10.1073 /$ pnas. 1514285112 .

Richardson EJ, Watson M. 2013. The automatic annotation of bacterial genomes. Briefings in Bioinformatics 14:1-12. DOI: 10.1093/bib/bbs007.

Roitman S, Hornung E, Flores-Uribe J, Sharon I, Feussner I, Béjà O. 2018. Cyanophage-encoded lipid desaturases: Oceanic distribution, diversity and function. ISME Journal 12:343-355. DOI: 10.1038/ismej.2017.159.

Rosenwasser S, Ziv C, Creveld SG van, Vardi A. 2016. Virocell Metabolism: Metabolic Innovations During Host-Virus Interactions in the Ocean. Trends in Microbiology 24:821832. DOI: 10.1016/j.tim.2016.06.006.

Roux S, Brum JR, Dutilh BE, Sunagawa S, Duhaime MB, Loy A, Poulos BT, Solonenko N, Lara E, Poulain J, Pesant S, Kandels-Lewis S, Dimier C, Picheral M, Searson S, Cruaud C, Alberti A, Duarte CM, Gasol JM, Vaqué D, Bork P, Acinas SG, Wincker P, Sullivan MB. 2016. Ecogenomics and potential biogeochemical impacts of globally abundant ocean viruses. Nature 537:689-693. DOI: 10.1038/nature19366.

Roux S, Emerson JB, Eloe-Fadrosh EA, Sullivan MB. 2017. Benchmarking viromics: An in silico evaluation of metagenome-enabled estimates of viral community composition and diversity. PeerJ 2017:1-26. DOI: 10.7717/peerj.3817.

Roux S, Enault F, Hurwitz BL, Sullivan MB. 2015. VirSorter: mining viral signal from microbial genomic data. PeerJ 3:e985. DOI: 10.7717/peerj.985.

Roux S, Krupovic M, Daly RA, Borges AL, Nayfach S, Schulz F, Cheng J-F, Ivanova NN, Bondy-Denomy J, Wrighton KC, Woyke T, Visel A, Kyrpides N, Eloe-Fadrosh EA. 2019. Cryptic inoviruses are pervasive in bacteria and archaea across Earth's biomes. Nature Microbiology:548222. DOI: 10.1101/548222.

Roux S, Krupovic M, Debroas D, Forterre P, Enault F. 2013. Assessment of viral community functional potential from viral metagenomes may be hampered by contamination with cellular sequences. Open Biology 3. DOI: 10.1098/rsob.130160.

PeerJ reviewing PDF | (2020:11:55638:2:0:NEW 20 Apr 2021) 
929

930

931

932

933

934

935

936

937

938

939

940

941

942

943

944

945

946

947

948

949

950

951

952

953

954

955

956

957

958

959

960

961

962

963

964

965

966

967

968

969

970

971

972

973

974

Sakowski EG, Arora-williams K, Tian F, Zayed AA, Zablocki O, Sullivan MB, Preheim SP. 2021. Interaction dynamics and virus-host range for estuarine actinophages captured by epicPCR. Nature Microbiology. DOI: 10.1038/s41564-021-00873-4.

Santos-Medellin C, Zinke LA, ter Horst AM, Gelardi DL, Parikh SJ, Emerson JB. 2020. Viromes outperform total metagenomes in revealing the spatiotemporal patterns of agricultural soil viral communities. DOI: 10.1017/CBO9781107415324.004.

Schloissnig S, Arumugam M, Sunagawa S, Mitreva M, Tap J, Zhu A, Waller A, Mende DR, Kultima JR, Martin J, Kota K, Sunyaev SR, Weinstock GM, Bork P. 2013. Genomic variation landscape of the human gut microbiome. Nature 493:45-50. DOI: 10.1038/nature11711.

Scola V, Ramond J-B, Frossard A, Zablocki O, Adriaenssens EM, Johnson RM, Seely M, Cowan DA. 2017. Namib desert soil microbial community diversity, assembly, and function along a natural xeric gradient. Microbial Ecology 1:193-203. DOI: 10.1007/s00248-0171009-8.

Shaffer M, Borton MA, Mcgivern BB, Zayed AA, Leanti S, Rosa L, Solden LM, Liu P, Narrowe AB, Daly RA, Bolduc B, Gazit MC, Smith GJ, Vik DR, Pope PB, Sullivan MB, Roux S, Wrighton KC. 2020. DRAM for distilling microbial metabolism to automate the curation of microbiome function. Nucleic Acids Research:1-18. DOI: 10.1093/nar/gkaa621.

Sharon I, Tzahor S, Williamson S, Shmoish M, Man-Aharonovich D, Rusch DB, Yooseph S, Zeidner G, Golden SS, MacKey SR, Adir N, Weingart U, Horn D, Venter JC, MandelGutfreund Y, Béjà O. 2007. Viral photosynthetic reaction center genes and transcripts in the marine environment. ISME Journal 1:492-501. DOI: 10.1038/ismej.2007.67.

Sigrist CJA, De Castro E, Cerutti L, Cuche BA, Hulo N, Bridge A, Bougueleret L, Xenarios I. 2013. New and continuing developments at PROSITE. Nucleic Acids Research 41:344-347. DOI: $10.1093 /$ nar/gks1067.

Solonenko SA, Sullivan MB. 2013. Preparation of metagenomic libraries from naturally occurring marine viruses. Elsevier Inc. DOI: 10.1016/B978-0-12-407863-5.00008-3.

Sommers P, Fontenele RS, Kringen T, Kraberger S, Porazinska DL, Darcy JL, Schmidt SK, Varsani A. 2019. Single-Stranded DNA Viruses in Antarctic Cryoconite Holes. Viruses.

Starr EP, Nuccio EE, Pett-Ridge J, Banfield JF, Firestone MK. 2019. Metatranscriptomic reconstruction reveals RNA viruses with the potential to shape carbon cycling in soil. Proceedings of the National Academy of Sciences. DOI: 10.1101/597468.

Sullivan MB, Huang KH, Ignacio-Espinoza JC, Berlin AM, Kelly L, Weigele PR, DeFrancesco AS, Kern SE, Thompson LR, Young S, Yandava C, Fu R, Krastins B, Chase M, Sarracino D, Osburne MS, Henn MR, Chisholm SW. 2010. Genomic analysis of oceanic cyanobacterial myoviruses compared with T4-like myoviruses from diverse hosts and environments. Environmental Microbiology 12:3035-3056. DOI: 10.1111/j.14622920.2010.02280.x.

Sullivan MB, Lindell D, Lee JA, Thompson LR, Bielawski JP, Chisholm SW. 2006. Prevalence and evolution of core photosystem II genes in marine cyanobacterial viruses and their hosts. PLoS Biology 4:1344-1357. DOI: 10.1371/journal.pbio.0040234.

Sullivan MJ, Petty NK, Beatson SA. 2011. Easyfig: A genome comparison visualizer. Bioinformatics 27:1009-1010. DOI: 10.1093/bioinformatics/btr039.

Trubl G, Jang H Bin, Roux S, Emerson JB, Solonenko N, Vik DR, Solden L, Ellenbogen J, Runyon AT, Bolduc B, Woodcroft BJ, Saleska SR, Tyson GW, Wrighton KC, Sullivan MB, Rich VI. 2018. Soil viruses are underexplored players in ecosystem carbon processing. 
975

976

977

978

979

980

981

982

983

984

985

986

987

988

989

990

991

992

993

994

995

996

997

998

999

1000

1001

1002

1003

1004

1005

1006

1007

1008

1009

1010

1011

1012

1013

1014

1015

1016

1017

1018

1019

1020

American society for microbiology 3:e0076-18. DOI: 10.1101/338103.

Trubl G, Roux S, Solonenko N, Li Y-F, Bolduc B, Eloe-Fadrosh E, Rich V, Sullivan M. 2019. Towards optimized viral metagenomes for double-stranded and single-stranded DNA viruses from challenging soils. PeerJ Preprints 7:e7265. DOI:

10.7287/peerj.preprints. 27640.

Tzahor S, Man-Aharonovich D, Kirkup BC, Yogev T, Berman-Frank I, Polz MF, Béjà O, Mandel-Gutfreund Y. 2009. A supervised learning approach for taxonomic classification of core-photosystem-II genes and transcripts in the marine environment. BMC Genomics 10. DOI: $10.1186 / 1471-2164-10-229$.

Villarroel J, Kleinheinz KA, Jurtz VI, Zschach H, Lund O, Nielsen M, Larsen MV. 2016. HostPhinder: A Phage Host Prediction Tool. Viruses:1-22. DOI: 10.3390/v8050116.

Wang W, Ren J, Tang K, Dart E, Ignacio-Espinoza JC, Fuhrman JA, Braun J, Sun F, Ahlgren NA. 2020. A network-based integrated framework for predicting virus-prokaryote interactions. NAR Genomics and Bioinformatics 2:1-19. DOI: 10.1093/nargab/lqaa044.

Warwick-Dugdale J, Solonenko N, Moore K, Chittick L, Gregory AC, Allen MJ, Sullivan MB, Temperton B. 2018. Long-read viral metagenomics enables capture of abundant and microdiverse viral populations and their niche-defining genomic islands. PeerJ:345041. DOI: $10.1101 / 345041$.

Waterhouse A, Bertoni M, Bienert S, Studer G, Tauriello G, Gumienny R, Heer FT, De Beer TAP, Rempfer C, Bordoli L, Lepore R, Schwede T. 2018. SWISS-MODEL: Homology modelling of protein structures and complexes. Nucleic Acids Research 46:W296-W303. DOI: $10.1093 /$ nar/gky427.

Wilhelm SW, Suttle CA. 1999. Viruses and nutrient cycles in the sea: viruses play critical roles in the structure and function of aquatic food webs. BioScience 49:781-788. DOI: 10.1161/CIRCULATIONAHA.111.030536.

Wommack KE, Nasko DJ, Chopyk J, Sakowski EG. 2015. Counts and sequences, observations that continue to change our understanding of viruses in nature. Journal of Microbiology 53:181-192. DOI: $10.1007 / \mathrm{s} 12275-015-5068-6$.

Yaffe E, Relman DA. 2020. Tracking microbial evolution in the human gut using Hi-C reveals extensive horizontal gene transfer, persistence and adaptation. Nature Microbiology 5:343353. DOI: $10.1038 / \mathrm{s} 41564-019-0625-0$.

Yang J, Zhang Y. 2015. I-TASSER server: New development for protein structure and function predictions. Nucleic Acids Research 43:W174-W181. DOI: 10.1093/nar/gkv342.

Yilmaz S, Allgaier M, Hugenholtz P. 2010. Multiple displacement amplification compromises quantitative analysis of metagenomes. Nature Methods 7:943-944. DOI: 10.1038/nmeth1210-943.

Zablocki O, Adriaenssens EM, Cowan D. 2015. Diversity and ecology of viruses in hyperarid desert soils. Applied and Environmental Microbiology 82:770-777. DOI: 10.1128/AEM.02651-15.

Zablocki O, Michelsen M, Burris M, Solonenko N, Warwick-Dugdale J, Ghosh R, Pett-Ridge J, Sullivan MB, Temperton B. 2021. VirION2: a short- And long-read sequencing and informatics workflow to study the genomic diversity of viruses in nature. PeerJ. DOI: $10.1101 / 2020.10 .28 .359364$.

Zheng T, Li J, Ni Y, Kang K, Misiakou M-A, Imamovic L, Chow BKC, Rode AA, Bytzer P, Sommer M, Panagiotou G. 2019. Mining, analyzing, and integrating viral signals from metagenomic data. Microbiome 7:42. DOI: 10.1186/s40168-019-0657-y.

PeerJ reviewing PDF | (2020:11:55638:2:0:NEW 20 Apr 2021) 
1021 Zhong Z, Rapp JZ, Wainaina JM, Solonenko NE, Maughan H, Carpenter SD, Cooper ZS, Jang B, Bolduc B, Deming JW, Sullivan B. 2020. Viral Ecogenomics of Arctic Cryopeg Brine and Sea Ice. mBio 5:1-17.

1025

1026

1027

1028

1029

Zimmermann L, Stephens A, Nam SZ, Rau D, Kübler J, Lozajic M, Gabler F, Söding J, Lupas AN, Alva V. 2018. A Completely Reimplemented MPI Bioinformatics Toolkit with a New HHpred Server at its Core. Journal of Molecular Biology 430:2237-2243. DOI: 10.1016/j.jmb.2017.12.007.

Zolfo M, Pinto F, Asnicar F, Manghi P, Tett A, Bushman FD, Segata N. 2019. Detecting contamination in viromes using ViromeQC. Nature Biotechnology. DOI: 10.1038/s41587019-0334-5. 
1031 Figure 1. The framework of dataset simulation strategies. First, the viral RefSeq, prokaryote, 1032 eukaryote, and plasmid genome sequences were fragmented, from 5' to 3' end direction, into 1033 non-overlapping fragments of different lengths, i.e. $L=500 \mathrm{bp}, 1 \mathrm{kbp}, 3 \mathrm{kbp}, 5 \mathrm{kbp}, 10 \mathrm{kbp}$, and

$103420 \mathrm{kbp}$ fragments. Then, these non-overlapping fragments were randomly sub-sampled to obtain 1035 simulated input datasets. For virus identification analysis, these simulated datasets were designed 1036 to resemble mock communities with different ratios of viral, prokaryote, eukaryote and plasmid 1037 sequences, i.e. virome_1 (10:1:0.1:0.01), virome_2 (10:1:0.01:1), bulk_1 (1:10:0.1:10), and 1038 bulk_2 (1:10:1:1). For viral classification analysis, simulated inputs were exclusively composed 1039 of fragmented viral genomes.

1040

1041 Figure 2. The viral identification analysis across datasets. (A-D) Pie-charts of the

1042 composition of the datasets depicted the different fragment sizes of the (i) virome_1, (ii)

1043 virome_2, (iii) bulk_1, and (iv) bulk_2.(E-H) The viral identification efficiency was calculated

1044 as Matthew's correlation coefficient (MCC), where 1 represents perfect efficiency, (I-L) percent

1045 of recall (\%), and (M-P) percent of false-discovery (\%) of DeepVirFinder, MetaPhinder,

1046 MARVEL, VIBRANT, and VirSorter. For DeepVirFinder, three cutoffs were evaluated, i.e.

1047 score $\geq 0.7, \geq 0.9, \geq 0.95$, and $p$-value $\leq 0.05$. For MARVEL, two cutoffs were used, i.e. scores of $1048 \geq 70 \%$ and $\geq 90 \%$. Next, we use two different versions of VirSorter, i.e. v1.05 and v1.10, and two 1049 cutoffs, i.e. category 1,2,3,4,5,6 and category 1,2,4,5. The upper error bars represent the mean of 1050 the replicates.

1051

1052 Figure 3. Viral classification analysis. (A) Percentage of the input sequences in a vConTACT 1053 v2 cluster and (B) Percentage of sequences assigned by VFP-class to a genus. The performance 1054 of VPF-class was calculated using confidence score (CS) and membership ratio (MR) thresholds 1055 of $\geq 0.2$ (Pons et al., 2021).

1056

1057 Figure 4. Proposed workflow and curation step for AMG identification and validation. The 1058 recommended steps of a candidate AMGs include, $(i)$ viral contig identification and quality 1059 assessment, (ii) AMG identification, genomic context assessment, and functional annotation, and 1060 (iii) further investigation of putative AMGs function. 
1062 Supplementary figure 1. Additional metrics for viral identification analysis across datasets.

1063 (A) The viral identification accuracy, (B) F1, (C) PVV, and (D) specificity of DeepVirFinder,

1064 MetaPhinder, MARVEL, VIBRANT, and VirSorter on the different fragment sizes of the $(i)$

1065 virome_1, (ii) virome_2, (iii) bulk_1, and (iv) bulk_2 (the composition of the datasets depicted as

1066 pie-charts). For DeepVirFinder, three cutoffs were evaluated, i.e. score $\geq 0.7, \geq 0.9, \geq 0.95$, and p-

1067 value $\leq 0.05$. For MARVEL, two cutoffs were used, i.e. scores of $\geq 70 \%$ and $\geq 90 \%$. Next, we use

1068 two different versions of VirSorter, i.e. v1.05 and v1.10, and two cutoffs, i.e. category 1,2,3,4,5,6

1069 and category $1,2,4,5$. The upper error bars represent the mean of the replicates (see more in

1070 Materials and Methods).

1071

1072 Supplementary figure 2. Results from viral identification analysis for VIBRANT with no

1073 virome flag, (A) MCC, (B) recall, (C) false discovery rate, (D) accuracy, (E) F1, (F) PVV, and

1074 (G) specificity of (i) virome_1, (ii) virome_2, (iii) bulk_1, and (iv) bulk_2 datasets. The upper

1075 error bars represent the mean of the replicates.

1076

1077 Supplementary figure 3. False-discovery rate of viral sequence identification tools when

1078 challenged with Archaea, Eukaryote and Plasmid datasets. In addition to the parameters used

1079 in (Figure 2 and Figure S1), two additional settings of VIBRANT, i.e. without virome flag,

1080 were added, and two VirSorter, i.e. without virome flag (standard setting) were also applied. A

1081 color gradient represents the viral identification tool. The upper error bars represent the mean of

1082 the replicates (see more in Materials and Methods).

1083

1084 Supplementary figure 4. Pairwise analyses of the combined viral identification tools

1085 efficiency parameters for varying genome sizes. Metrics used included (A) MCC, (B) recall,

1086 (C) false discovery rate, (D) accuracy, (E) F1, (F) PVV, and (G) specificity of virome_1,

1087 virome_2, bulk_1, and bulk_2 datasets. The Wilcoxon test was used to compare fragment sizes

1088 (non-parametric) of the overall performance of viral identification. The 20k dataset was used as

1089 reference data (see more in Materials and Methods). Only significant comparison is shown as

1090 follows, $*$ : $p$-value $\leq 0.05 ; * *$ : $p$-value $\leq 0.01 ; * * *: p$-value $\leq 0.001 ; * * * *: p$-value $\leq 0.0001$.

1091 
1092 Supplementary figure 5. Gene-sharing network topology and performances. (A) the gene-

1093 sharing network for genome $3 \mathrm{kbp}$ size, and (B) complete-genome. (C) the count of new viral

1094 clusters and clusters with reference genomes, and (D) the percentage of the overlapping, outliers, 1095 and singletons.

1097 Supplementary figure 6. Percentage of 'correct' genus-assignments. (A) vConTACT v2 and

1098 (B) VFP-class. The analysis was performed by evaluating the correct genus assignment in 1099 comparison to the complete genomes. Only the genus-affiliated genomes were considered in the 1100 evaluation for vConTACT v2.

1102 Supplementary figure 7. Comparison of the performances of viral gene-sharing network1103 based classification, vConTACT v2 across fragment size, (A) Accuracy (Acc), (B) Clustering1104 wise separation (Sep), (C) clustering-wise PPV (PPV), (D) clustering-wise sensitivity (Sn), (E) 1105 cluster-wise separation $\left(\operatorname{Sep}_{c l}\right)$, and $(\mathbf{F})$ complex-wise sensitivity $\left(\operatorname{Sep}_{c o}\right)$. The complete formula 1106 can be seen in Jang et al., (2019).

\section{Supplementary figure 8. Performance evaluation of VipTree and VIRIDIC across}

1109 fragment sizes. (A) ViPTree, and (B) VIRIDIC. Because VIRIDIC and ViPTree do not provide

1110 a taxonomic affiliation per se but a distance matrix, the differences in performance between

1111 different fragment sizes were calculated by comparing the pairwise distances obtained from the

1112 fragment sizes with the distances obtained from the complete genomes for the same pair,

1113 expressed as a percentage relative to the distance obtained from complete genomes. While these

1114 percentage reflects differences in the similarity matrix obtained with different fragment sizes for

1115 a given tool, these cannot be directly compared between tools or to the performance metrics used

1116 to assess the impact of genome fragmentation on the taxonomic classification obtained by

1117 vConTACT v2 and VPF-Class. 


\section{Table $\mathbf{1}$ (on next page)}

Table 1

The comparison of the commonly-used viral identification tools 
1 Table 1. The comparison of the commonly-used viral identification tools

\begin{tabular}{|c|c|c|c|c|}
\hline Tool & Approach & Basic mode & $\begin{array}{l}\text { Ability to process modern- } \\
\text { scale (viral) metagenomes } \\
\text { Scalability }\end{array}$ & Reference \\
\hline VirSorter & $\begin{array}{l}\text { Gene-content-based tool. Features } \\
\text { include enrichment in viral-like genes, } \\
\text { depletion in PFAM hits, enrichment in } \\
\text { short genes, and depletion in coding } \\
\text { strand changes }\end{array}$ & $\begin{array}{l}\text { Permissive cut-off category 1-6 } \\
\text { Conservative category } 1245 \\
\text { Setting for -virome, } \\
\text { enable virome decontamination mode }\end{array}$ & Yes & (Roux et al., 2015) \\
\hline MARVEL & $\begin{array}{l}\text { Gene-content-based tool. Features include } \\
\text { average gene length, average spacing } \\
\text { between genes, density of genes, } \\
\text { frequency of strand shifts between } \\
\text { neighboring genes, ATG relative } \\
\text { frequency, and fraction of genes with } \\
\text { significant hits against the pVOGs } \\
\text { database. }\end{array}$ & $\begin{array}{l}\text { Permissive cut-off } \geq 70 \% \\
\text { Conservative } \geq 90 \%\end{array}$ & Yes & (Amgarten et al., 2018) \\
\hline VIBRANT & $\begin{array}{l}\text { Gene-content-based tool. Features } \\
\text { include ratio of KEGG hits, ratio of VOG } \\
\text { hits, ratio of PFAM hit, as well as } \\
\text { presence of key viral-like genes (e.g. } \\
\text { nucleases, integrase, etc) }\end{array}$ & Default & Yes & $\begin{array}{l}\text { (Kieft, Zhou \& } \\
\text { Anantharaman, 2020) }\end{array}$ \\
\hline MetaPhinder & $\begin{array}{l}\text { Integrated analysis of BLASTn hits to a, } \\
\text { bacteriophage database, no gene } \\
\text { prediction or amino acid-level } \\
\text { comparison }\end{array}$ & Default & Yes & (Jurtz et al., 2016) \\
\hline DeepVirFinder & $\begin{array}{l}\text { K-mer based similarity to viral and host } \\
\text { databases, no gene prediction or amino } \\
\text { acid-level comparison }\end{array}$ & $\begin{array}{l}\text { Permissive cut-off score } \geq 0.7 \text {, } \\
\text { Medium } \geq 0.90, \\
\text { Conservative } \geq 0.95, \text { and } p \text {-value } \\
\leq 0.05\end{array}$ & Yes & (Ren et al., 2019) \\
\hline VirMiner & $\begin{array}{l}\text { Gene-content-based tool. Features include } \\
\text { ratio of hits to KO, ratio of hits to POGs, } \\
\text { ratio of hits to PFAM, and presence of } \\
\text { hallmark genes }\end{array}$ & $\begin{array}{l}\text { Default. Web server: } \\
\text { http://147.8.185.62/VirMiner/ }\end{array}$ & No & (Zheng et al., 2019) \\
\hline PHASTER & $\begin{array}{l}\text { Gene-content-based tool. Features include } \\
\text { number of phage-like genes, with } \\
\text { additional annotation of e.g. tRNA to } \\
\text { better predict prophage boundaries. }\end{array}$ & $\begin{array}{l}\text { Default. Web server: } \\
\text { https://phaster.ca }\end{array}$ & No & (Arndt et al., 2017) \\
\hline
\end{tabular}


Table 2 (on next page)

Table 2

Auxiliary metabolic genes (AMGs) curation guidelines 
1 Table 2. Auxiliary metabolic genes (AMGs) curation guidelines

\begin{tabular}{|c|c|c|c|c|}
\hline Parameters & Analysis program & Cut-off ${ }^{\mathrm{a}}$ & Note & Reference \\
\hline \multirow{2}{*}{$\begin{array}{l}\text { Viral assembled contig } \\
\text { quality assessment }\end{array}$} & CheckV & Complete viral contigs & - & (Nayfach et al., 2020) \\
\hline & ViromeQC & Default & - & (Zolfo et al., 2019) \\
\hline \multirow[t]{2}{*}{ AMG identification } & VIBRANT & Default & - & (Kieft, Zhou \& Anantharaman, 2020) \\
\hline & DRAM-v & Default & $\begin{array}{l}\text { Putative AMG criteria: } \\
\text { AMG score } 1-3 \text {, and } \\
-\mathrm{M} \text { and }-\mathrm{F} \text { flag. }\end{array}$ & (Shaffer et al., 2020) \\
\hline \multirow[t]{5}{*}{$\begin{array}{l}\text { Conserved residues and } \\
\text { active sites }\end{array}$} & PROSITE & Default & $\begin{array}{l}\text { PROSITE collection of motifs } \\
\text { (ftp://ftp.expasy.org/databases/pros } \\
\text { ite/prosite.dat) database }\end{array}$ & (Sigrist et al., 2013) \\
\hline & HHPred & Default & database: PDB_mmCIF70_23_Jul & (Zimmermann et al., 2018) \\
\hline & BPROM & $\begin{array}{l}\text { Linear discriminant function } \\
(\mathrm{LDF})>2.75\end{array}$ & $\begin{array}{l}\text { Bacteria } \sigma-70 \text { Promoters. In } \\
\text { intergenic region or within } 10 \mathrm{bp} \\
\text { of start or stop of ORF }\end{array}$ & (Richardson \& Watson, 2013) \\
\hline & TransTermHP & Confidence score $>90 \%$ & Terminators search & $\begin{array}{l}\text { (Kingsford, Ayanbule \& Salzberg, } \\
\text { 2007) }\end{array}$ \\
\hline & ARNold & Default & Terminators search & (Macke et al., 2001) \\
\hline \multirow[t]{4}{*}{ Protein structural } & Phyre $^{2}$ & $\begin{array}{l}100 \% \text { confident and } \geq 70 \% \\
\text { alignment coverage }\end{array}$ & $\begin{array}{l}\text { Secondary and tertiary structure } \\
\text { search }\end{array}$ & (Kelly et al., 2015) \\
\hline & SWISS-MODEL & $\begin{array}{l}\text { Global Model Quality } \\
\text { Estimation (GMQE) score above } \\
0.5\end{array}$ & Quaternary structure & (Waterhouse et al., 2018) \\
\hline & I-TASSER & Default & Protein structural & (Yang \& Zhang, 2015) \\
\hline & TMHMM & Default & Transmembrane domain & (Krogh et al., 2001) \\
\hline $\begin{array}{l}\text { Synonymous and non- } \\
\text { synonymous mutation }\end{array}$ & MetaPop & $\begin{array}{l}<0.3 \text { represent strong purifying } \\
\text { selection }\end{array}$ & Calculate the $p \mathrm{~N} / p \mathrm{~S}$ & $\begin{array}{l}\text { (Schloissnig et al., 2013; Gregory et al., } \\
2020)\end{array}$ \\
\hline
\end{tabular}

$2{ }^{\mathrm{a}}$ The recommendation cut-offs that can be used in each step of AMGs curation 


\section{Figure 1}

The framework of dataset simulation strategies.

First, the viral RefSeq, prokaryote, eukaryote, and plasmid genome sequences were fragmented, from 5 ' to 3 ' end direction, into non-overlapping fragments of different lengths, i.e. $L=500 \mathrm{bp}, 1 \mathrm{kbp}, 3 \mathrm{kbp}, 5 \mathrm{kbp}, 10 \mathrm{kbp}$, and $20 \mathrm{kbp}$ fragments. Then, these nonoverlapping fragments were randomly sub-sampled to obtain simulated input datasets. For virus identification analysis, these simulated datasets were designed to resemble mock communities with different ratios of viral, prokaryote, eukaryote and plasmid sequences, i.e. virome_1 (10:1:0.1:0.01), virome_2 (10:1:0.01:1), bulk_1 (1:10:0.1:10), and bulk_2 (1:10:1:1). For viral classification analysis, simulated inputs were exclusively composed of fragmented viral genomes.
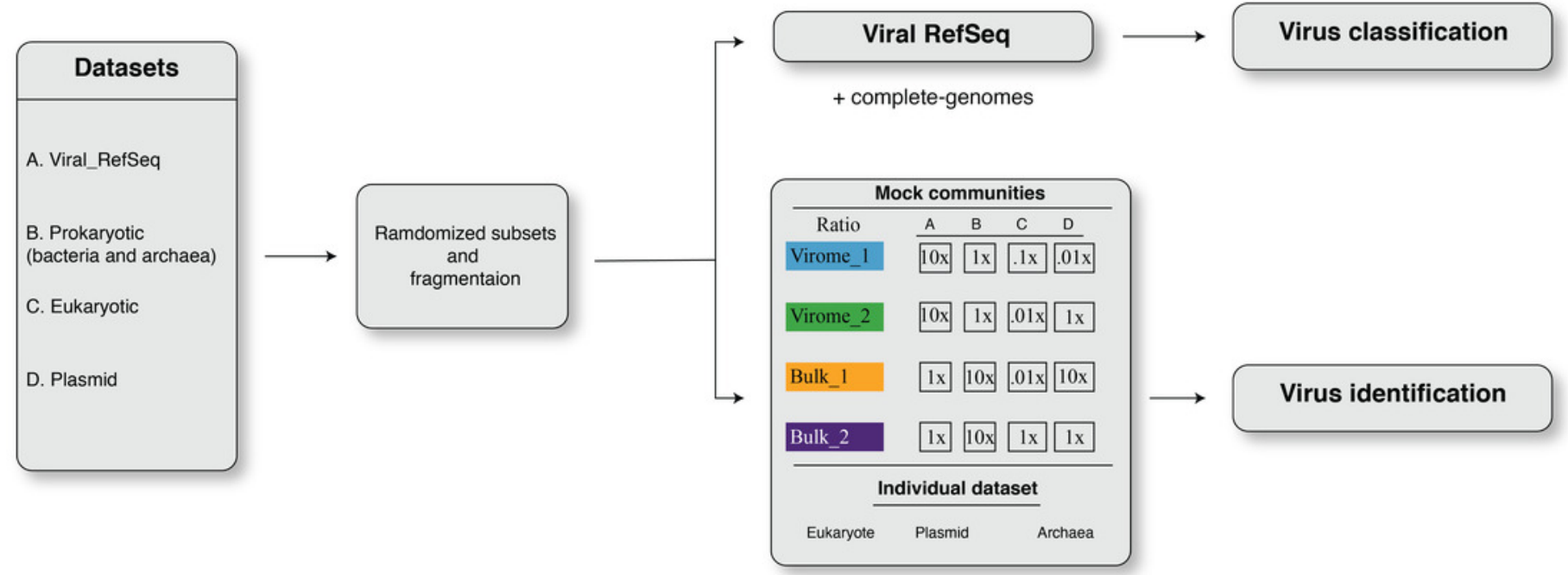


\section{Figure 2}

The viral identification analysis across datasets

Figure 2. The viral identification analysis across datasets. (A-D) Pie-charts of the composition of the datasets depicted the different fragment sizes of the (i) virome_1, (ii) virome_2, (iii) bulk_1, and (iv) bulk_2. (E-H) The viral identification efficiency was calculated as Matthew's correlation coefficient (MCC), where 1 represents perfect efficiency,(I-L) Percent of recall (\%), and (M-P) Percent of false-discovery (\%) of DeepVirFinder, MetaPhinder, MARVEL, VIBRANT, and VirSorter. For DeepVirFinder, three cutoffs were evaluated, i.e. score $\geq 0.7, \geq 0.9, \geq 0.95$, and p-value $\leq 0.05$. For MARVEL, two cutoffs were used, i.e. scores of $\geq 70 \%$ and $\geq 90 \%$. Next, we use two different versions of VirSorter, i.e. v1.05 and v1.10, and two cutoffs, i.e. category $1,2,3,4,5,6$ and category $1,2,4,5$. The upper error bars represent the mean of the replicates. 
A prokaryote (1) $\square$ plasmid (0.01)

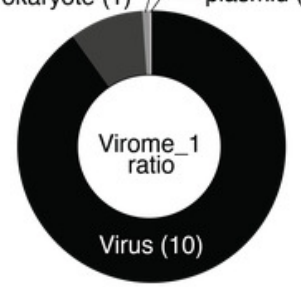

E

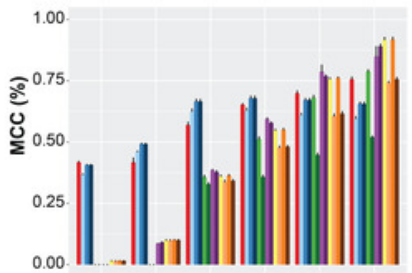

I

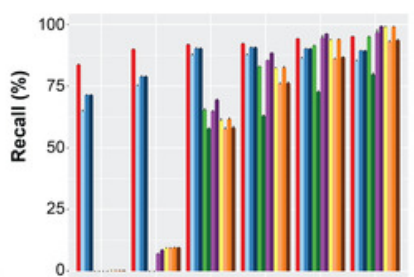

M

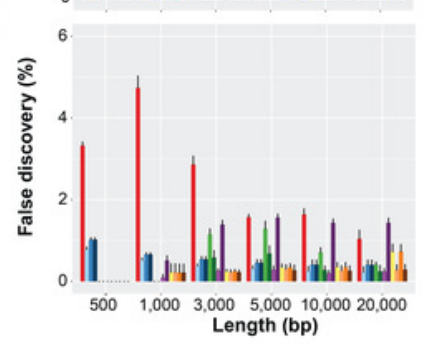

\section{B}

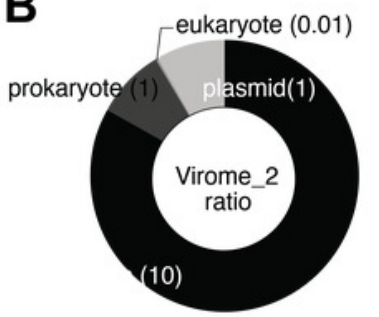

$\mathbf{F}_{1.00}$

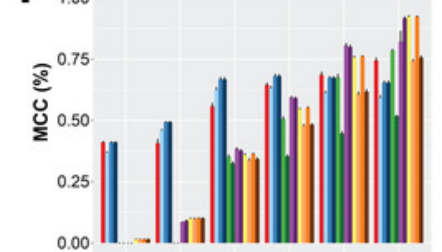

$\boldsymbol{J}^{0.00}$

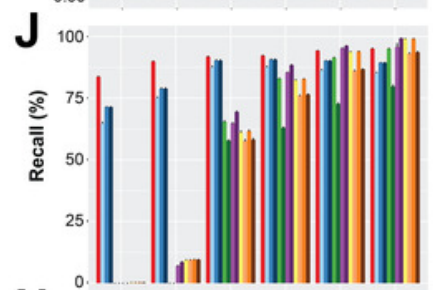

$\mathbf{N}_{6}$

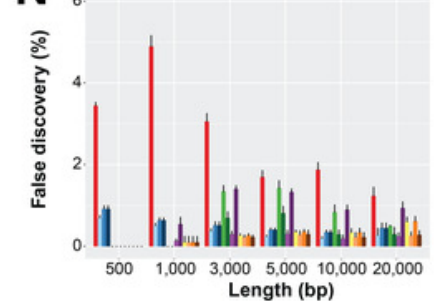

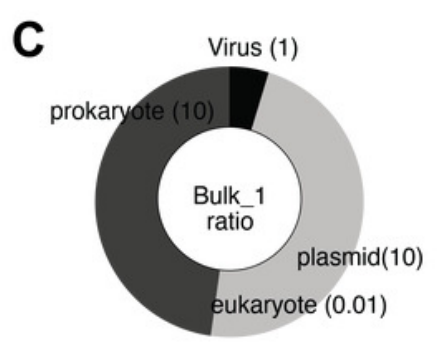

$\mathbf{G}_{100}$

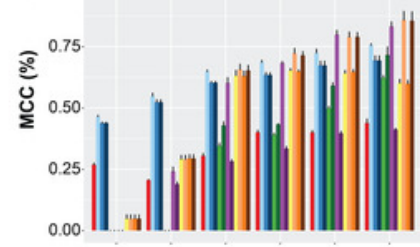

K 100

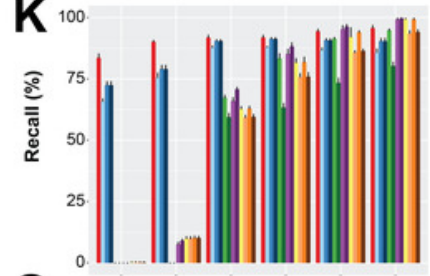

$\mathbf{O}_{100}$

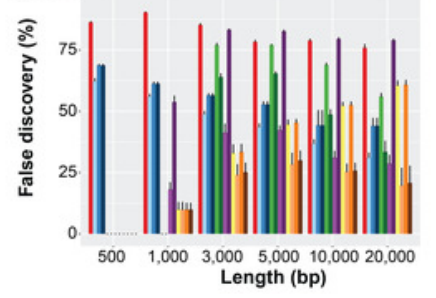

D

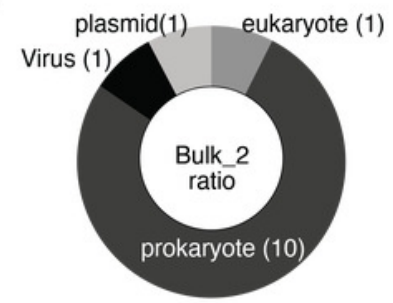

$\mathbf{H}_{1.00}$

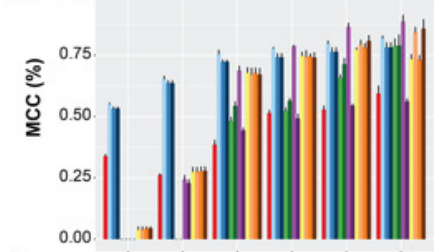

L 100

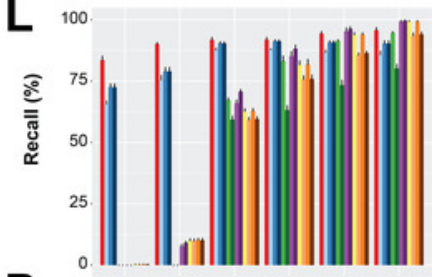

$\mathbf{P}_{100}$

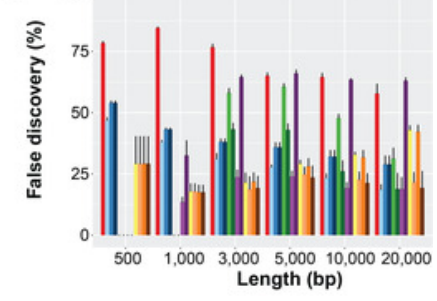




\section{Figure 3}

Viral classification analysis

(A) Percentage of the input sequences in a vConTACT v2 cluster and (B) Percentage of sequences assigned by VFP-class to a genus. The performance of VPF-class was calculated using confidence score (CS) and membership ratio (MR) thresholds of $\geq 0.2$ (Pons et al., 2021)

A.

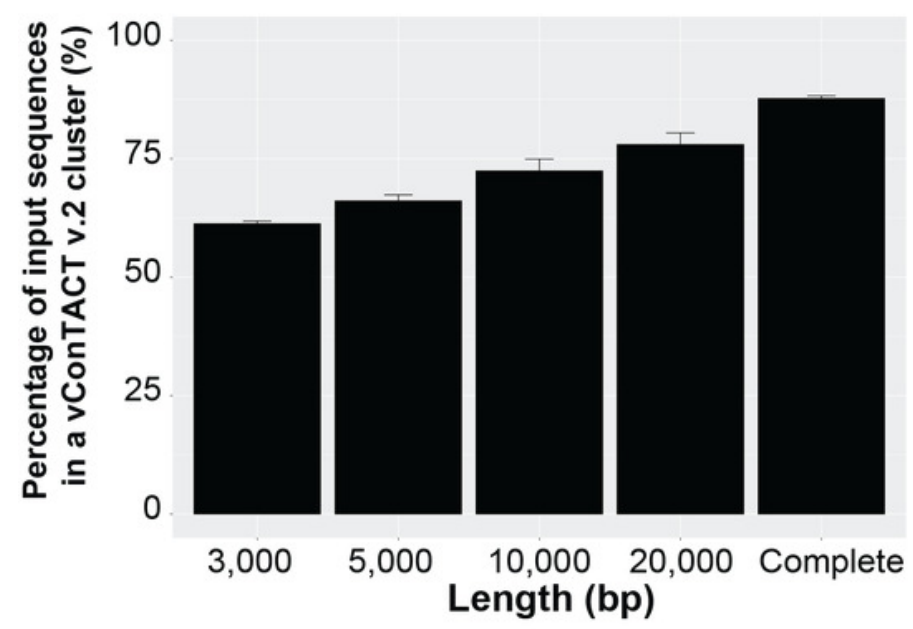

B.

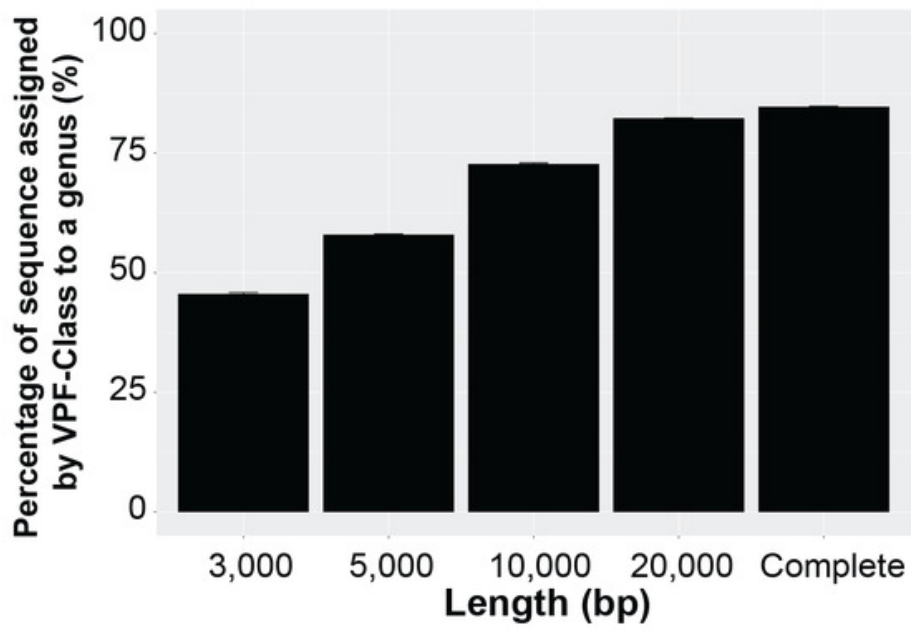




\section{Figure 4}

Proposed workflow and curation step for AMG identification and validation

The recommend ed steps of a candidate AMGs includ e , (i) viral contig identification and quality assessment, (ii) AMG identification, genomic context assessment, and functional annotation, and (iii) further investigation of putative AMGs function. 


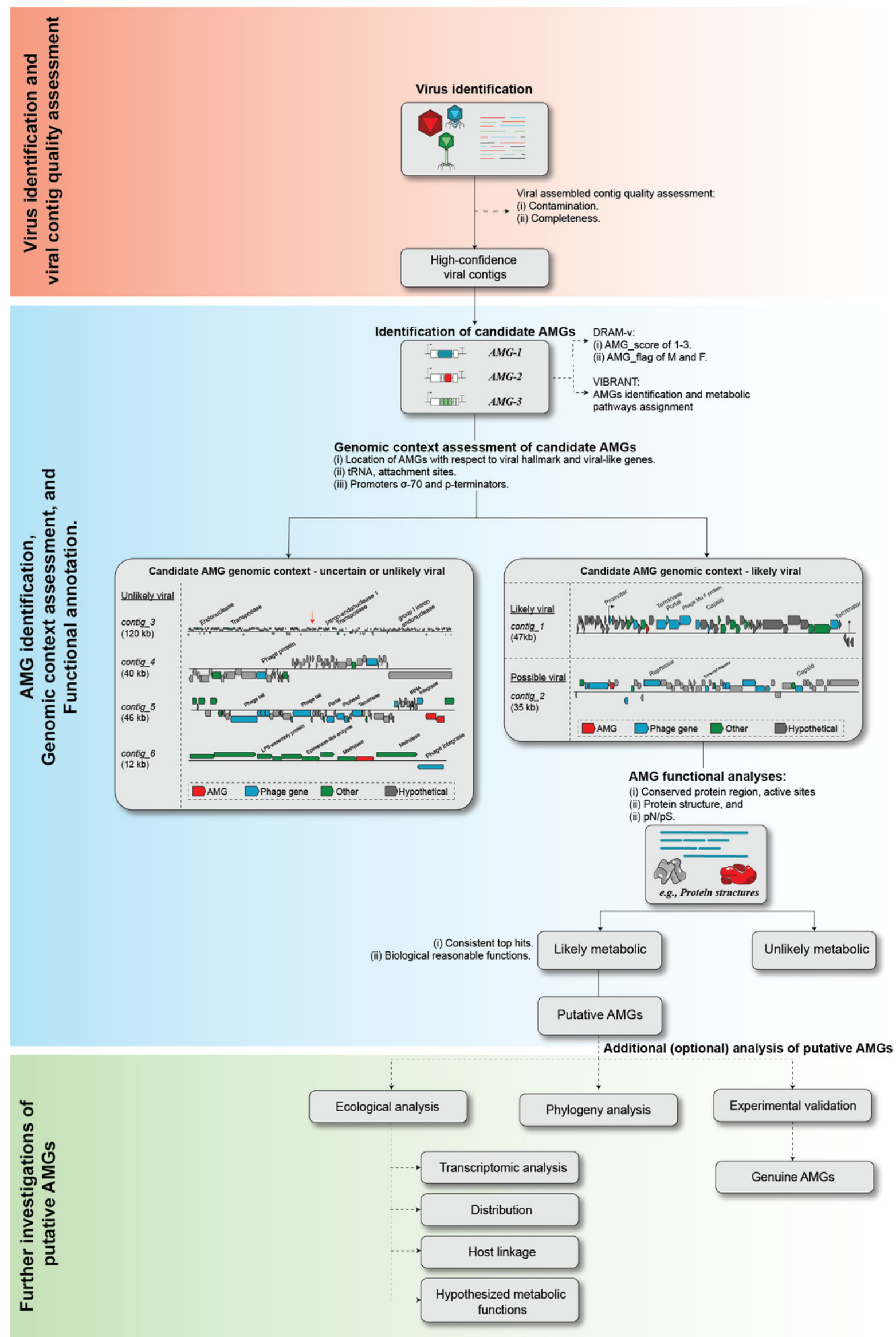

